\title{
Impacts of Cumulus Convection Parameterization on Aqua-planet AGCM Simulations of Tropical Intraseasonal Variability
}

\author{
Myong-In LEE ${ }^{1}$ \\ Climate Environment System Research Center, Seoul National University, Seoul, Korea \\ In-Sik KANG \\ School of Earth and Environmental Sciences, Seoul National University, Seoul, Korea \\ and \\ Brian E. MAPES \\ NOAA-CIRES Climate Diagnostics Center, Boulder, Colorado, USA
}

(Manuscript received 17 April 2002, in revised form 3 May 2003)

\begin{abstract}
Using an aqua-planet version of an atmospheric general circulation model (AGCM), the dependence of the tropical intraseasonal oscillation (ISO) simulation on the cumulus parameterization was examined with three different cumulus schemes-simplified Arakawa-Schubert, Kuo, and moist convective adjustment. The simulated intensity and propagation characteristics of the ISO depend significantly on the choice of cumulus scheme, in which more constrained convection scheme produces stronger intraseasonal variability in tropics.

Mean thermodynamic state and the Intertropical Convergence Zone (ITCZ) structure also vary among the simulations, demonstrating that the ISO variability and the mean states are mutually dependent. Following Tokioka et al. (1988), the simplified Arakawa-Schubert scheme was modified by posing a minimum entrainment rate constraint for cumuli, and the relationship between tropical intraseasonal variability and zonal mean rainfall structure was examined. More constraining deep convections, the tropical ISO variability becomes stronger with narrower ITCZ structures.

Vertical and horizontal structures of eastward propagating waves appeared in the aqua-planet experiments were further investigated. The vertical structures of propagating waves are consistent with observations of the Madden-Julian Oscillation, but the vertical profile of ISO-modulated heating exhibits a middle-heavy structure and the simulated waves show relatively faster propagations compared with the observed. The horizontal composite structures show the boundary-layer moisture frictional convergence to the east, and divergence to the west of the convective region, and this suggests that a frictional Kelvin wave-CISK mechanism is important to these eastward propagating waves.
\end{abstract}

Corresponding author: In-Sik Kang, School of Earth and Environmental Sciences, Seoul National University, Kwanak-Ku, Seoul 151-742, Korea.

E-mail: kang@climate.snu.ac.kr

1 Present affiliation: Goddard Earth Sciences and Technology Center, University of Maryland, Baltimore County, USA.

(C) 2003, Meteorological Society of Japan

\section{Introduction}

Most contemporary atmospheric general circulation models (AGCMs) cannot simulate the basic characteristics of the tropical Intraseasonal Oscillation or Madden-Julian Oscillation (Madden and Julian 1971; hereafter ISO) appropriately. In an evaluation of 15 AGCMs as 
part of the Atmospheric Model Intercomparison Project (AMIP, Gates 1992), Slingo et al. (1996) indicated typical shortcomings of too-weak intensity and too-fast propagation, and they suggested that more efforts are needed to achieve better representations of the ISO in global models. Because deep convection is so central to the ISO, its representation in models hinges on the details of cumulus parameterization.

Hints on how to improve too-weak and toofast ISO activity may be gleaned from the instability and propagation characteristics of largescale wave modes found in previous theoretical and idealized model calculations. Both characteristics are apparently sensitive to the vertical profile of diabatic heating by deep convection (as discussed below, reviewed also in Lin et al. 2003). Another key issue is the convective "closure", the set of rules by which a model determines the magnitude of convective heating, rainfall, etc., as a function of the grid-resolved fields.

One prominent theoretical approach has been to use so-called "wave-CISK" models, in which the heating profile is specified explicitly, and the closure is based on moisture convergence, or just convergence, if the basic-state humidity is fixed (Lau and Peng 1987; Chang and Lim 1988; and Takahashi 1987). Regarding the growth of disturbances, wave-CISK calculations by Cho and Pendlebury (1997) showed that unstable large-scale modes emerge only when the heating profile is sufficiently topheavy, i.e., when the specified heating profile contains a sufficient amount of the second vertical mode of the troposphere. This finding is supported by the model results of Mapes (2000), using a very different closure. Regarding the propagation speed of disturbances, Lau and Peng (1987) showed a slowing when their specified heating profile had its maximum at a lower level. They compared only middle-heavy and bottom-heavy profiles, but we may speculate that top-heavy heating might similarly reduce the propagation speed in their model relative to the middle-heavy heating profile.

In full-physics AGCMs, both the magnitude and profile of convective heating are determined internally by the cumulus parameterization, often in complicated ways. For example, the Arakawa-Schubert scheme (Arakawa and Schubert 1974) and its variants such as the Relaxed Arakawa-Schubert (RAS) scheme (Moorthi and Suarez 1992), determine the cumulus heating and associated moisture tendencies by use of the so-called "quasi-equilibrium" assumption, in concert with complicated entrainment and detrainment structures formulated for ensembles of idealized convective plumes. In the moist convective adjustment (MCA) scheme (Manabe et al. 1965), the heating profile is an unforeseeable result of repeated application of governing rules, which are localized in the vertical. Even in the simpler Kuo scheme (1974), with a CISK-type closure based on large-scale moisture convergence, the magnitude and vertical distribution of heating depend on a poorly-known $b$-parameter dividing total moisture convergence into precipitation or moistening. In all these schemes, the cumulus heating depends on local conditions where the scheme acts, and these local conditions depend on the model's climate biases as well as its transient disturbance characteristics. Therefore, it is not simple to relate the failures of most AGCMs to simple wave-CISK theory or other direct logical inferences. One simply has to conduct experiments with the numerical model and diagnose the results.

Regarding the tropical ISO and cumulus convection schemes in the AGCMs, many studies have been carried out (recent examples include Slingo et al. 1996; Chao and Deng 1998; Wang and Schlesinger 1999; Maloney and Hartmann 2001). Slingo et al. (1996) suggested that cumulus parameterizations with buoyancy-based closures in AGCMs seem to be more favorable than those with moisture-convergence closures to increase the tropical transient activity and hence the ISO strength, but there were many exceptions to this rule. This lack of clear relationship may be due to various specific implementations of cumulus schemes, and their feedback with other physical processes existing within the models, as well as the different dynamical and numerical techniques and horizontal resolutions. For this reason, it is probably more illuminating to evaluate the sensitivity of ISO simulations to the cumulus convection scheme within a single model by differing cumulus schemes, or parameters within a single scheme.

Chao and Deng (1998) showed that the simulated ISO is significantly affected when the cu- 
mulus scheme is changed within a single model. They found that, among the three different cases of cumulus scheme-the moist convective adjustment (MCA), the Relaxed ArakawaSchubert (RAS), and the simple convection scheme of Chao and Lin (1994)-the experiment with MCA is most successful in simulating the eastward propagation patterns of the ISO, while the experiment with the RAS scheme is the poorest. They discussed the slow growth rate of cloud clusters in the RAS, speculating that it might be due to the quasiequilibrium assumption, which does not allow large fluctuations of convective instability. This logic suggests that transient variability might be increased by allowing larger deviations from the quasi-equilibrium, for example through some additional conditions, or thresholds restricting the occurrence of convection.

Wang and Schlesinger (1999) examined the effect of humidity thresholds for convection development within three different cumulus parameterizations (Arakawa-Schubert, Kuo, and MCA) in a single AGCM. They found that, for all three schemes, the simulated ISO depends sensitively on this critical relative humidity criterion, in the sense anticipated above: greater variability occurs for more restrictive thresholds. The humidity threshold apparently allows moisture to accumulate for some time before being condensed in the active phase of largescale waves. Maloney and Hartmann (2001) also examined ISO simulations with three different convection schemes, finding that the McRAS scheme (Sud and Walker 1999) gave the most realistic variability. However, they found only a small dependence of the McRASsimulated ISO on boundary-layer $\mathrm{RH}$ threshold, of opposite sign to the result of Wang and Schlesinger. They reconciled these findings by noting that, while the simulated ISO involved preconditioning of the atmosphere through moisture storage and discharge, the humidity variations occurred mainly above the boundary layer, so that "the use of critical $\mathrm{RH}$ within the boundary layer ... may be an oversimplification of the preconditioning process."

The beneficial effects on ISO simulation of having stringent constraints on convection were also discussed by Tokioka et al. (1988) and Itoh (1989). In particular, Tokioka et al. (1988) modified the Arakawa-Schubert cumu- lus scheme by introducing a minimum entrainment rate constraint, depending on the planetary boundary layer (PBL) depth. The justification is that if convective plumes begin as eddies in the PBL, their width to which entrainment rate is proportional inversely should scale with PBL depth. Implementing this criterion caused an eastward propagating oscillation with a period of about 30 days to emerge clearly.

Based on these previous studies, it appears to be the case that: 1) Cumulus parameterization is the most likely element in AGCM modeling to produce better ISO representations. 2) The results do not depend simply on the basic type of scheme: even a small modification within a scheme (Tokioka et al. 1988; Wang and Schlesinger 1999) can cause drastic changes in the ISO variability within the model. 3 ) In general, restrictions on the cumulus convection tend to increase transient variability. Still, some questions remain as opportunities for the present study, if only to generalize prior findings through the use of an independent model.

One challenging issue for modeling studies on ISO is how a convection scheme indirectly affects ISO variability through changes in the mean climatological states. For example, Maloney and Hartmann (2001) showed that the effect of a change to the convection schemedowndrafts, in this case-was predominantly through changes to the mean state, through an experiment in which the downdraft tendencies were replaced by their climatological time-mean values. Important aspects of the mean state include not only the general tropical thermodynamic profiles, but also the latitude at which convection is most active. Wang and Schlesinger (1999) showed that the simulations in which the ISO variability is stronger are those in which precipitation is stronger on the equator. Maloney and Hartmann (2001) speculate that equatorial frictional convergence, an apparently important mechanism in the ISO (Maloney and Hartmann 1998, 2001), is most effective at organizing convection when the convection is on the equator. Of course, the mean state (latitude of maximum tropical convection) and the characteristics of transient disturbances, are mutually interdependent, as discussed by Hess et al. (1993). 
The main objective of this study is to investigate the impacts of cumulus parameterization on the simulated tropical intraseasonal variability in the AGCM. In particular, the interdependent relationship between the mean climatological states and the tropical ISO variability, will be explored by focusing on the indirect influences of cumulus scheme on the simulated zonal mean rainfall patterns and thermodynamic vertical profiles. The cumulus schemes we investigated are the ArakawaSchubert scheme (Arakawa and Schubert 1974) simplified by Numaguti et al. (1995), the Kuo (1974), and the moist convective adjustment (Manabe et al. 1965). We conducted a set of aqua-planet (Hayashi and Sumi 1986) experiments, because it is more useful for interpreting the different responses of the model due to the change of cumulus scheme or parameters, and investigating the interaction between model dynamics and physical parameterizations. Moreover, radiation is fixed for simplicity at every time step by prescribing a zonally uniform radiative cooling rate, the same in all experiments, so that cloud-radiation feedback is disabled in the model. Prescribing radiation also tends to reduce the differences in the mean climate states of the different model runs. The complementary problem was examined in a companion paper (Lee et al. 2001), which contrasts aqua-planet experiments with fixed and interactive radiation while leaving the cumulus parameterization unchanged. It is more difficult to interpret the differences among model runs in which both convection and radiation vary. We also conducted the realistic ISO simulation with the fully interactive physics and the actual land-ocean distribution to examine how the aqua-planet effects of the cumulus scheme modifications translate to Earth.

In section 2, we describe the model used, convection schemes and the experimental design. Section 3 discusses the different transient characteristics associated with tropical ISO and time-mean climatology appeared in the aquaplanet experiments when the three standard cumulus schemes are applied respectively. We further discuss the influence of minimum cumulus entrainment threshold in the simplified Arakawa-Schubert scheme. Section 4 describes the vertical structures: different thermodynamic state stratifications and ISO-modulated condensational heating profiles. We also investigate the vertical structure of propagating waves through the composite analysis. Eastward propagation mechanisms are discussed in section 5 with the horizontal composites of lowlevel moisture and circulation field. In section 6 , we present the ISO variability appeared in the realistic integrations of AGCM including full interactive physics and realistic geometry. Finally, we present discussions and conclusions in section 7 .

\section{Model and experiments}

\subsection{Model description}

The model used in this study is the atmospheric general circulation model developed by Seoul National University (SNUGCM; Kim et al. 1998), and identical to that described in Lee et al. (2001). The SNUGCM is mainly based on the Center for Climate System Research (CCSR)/National Institute for Environmental Studies (NIES) AGCM (Numaguti et al. 1995), but has several major changes including nonprecipitating shallow convection (enhanced diffusion, Tiedtke 1983), non-local PBL/vertical diffusion scheme (Holtslag and Boville 1993), and land surface process by the National Center for Atmospheric Research (NCAR) Community Climate Model (CCM3) land surface model (Bonan 1996). The radiation process is parameterized by the 2 -stream $k$-distribution scheme (Nakajima and Tanaka 1986). The cumulus scheme is a simplified version (Numaguti et al. 1995) based on the Arakawa-Schubert scheme, and this will be explained more in the next subsection. The large-scale condensation is based on Le Treut and Li (1991). Modification in the characteristic precipitation time scale in Lee et al. (2001) is not applied in the present study. It is noted that the shallow convection has a non-precipitating type in our model, so that the condensational heating can be produced only by the cumulus convection and large-scale condensation schemes. The orographic gravity wave drag is also parameterized based on McFarlane (1987). In this study, T31 truncation was used with 20 vertical levels.

\subsection{Convection schemes and parameters}

The standard cumulus scheme in the SNUGCM is a simplified version (Numaguti 
et al. 1995) of the Arakawa-Schubert scheme (hereafter SAS). As in the original ArakawaSchubert scheme, it assumes a hypothetical ensemble of cumulus cloud types, defined by their different entrainment rates (or cloud-top altitudes). Each cloud type entrains mass from the environment up to the cloud top, where all mass detrains. Each cloud type is completely characterized by the mass flux at cloud base $\left(M_{B}\right)$ and entrainment rate $(\mu)$. The closure, determining $M_{B}$ for each cloud type, uses the cloud work function $A_{i}$ of the $i$-th cloud type, defined as

$$
A_{i}=\int_{z_{B}}^{z_{T}} \frac{g}{\bar{T}}\left(T_{v}^{i}-\bar{T}_{v}\right) \eta d z,
$$

where $g$ is gravity acceleration, $z$ height, $z_{B}$ the cloud base level (determined by lifting condensation level), $z_{T}$ the cloud top height (defined by a zero-buoyancy condition), $T_{v}^{i}$ indicates the virtual temperature of the $i$-th cloud, and $\bar{T}_{v}$ is the grid-mean environmental value. $\eta$ is a normalized mass flux, with which the entrainment rate $\mu$ is determined as

$$
\mu=\frac{\partial \eta}{\partial z},
$$

in which the normalized mass flux is assumed to be a linear function of height, as in Moorthi and Suarez (1992).

The original Arakawa-Schubert scheme is closed by the quasi-equilibrium assumption (Arakawa and Schubert 1974), in which the rate of stabilization by cumulus mass flux equals the rate of destabilization by the largescale processes, for each cumulus cloud type (depth). The simplified scheme of this study (SAS) instead assumes that cumulus mass fluxes relax the column toward neutral stability with a specified adjustment time scale. Specifically, a perturbed cloud work function $A^{\prime}$ is computed in response to a small trial mass flux $M_{0}$, and then the appropriate amount of cloudbase mass flux is calculated as

$$
M_{B}=M_{0} \frac{A}{A-A^{\prime}} \frac{\Delta t}{\tau},
$$

where $\Delta t$ is the time step of the model, and $\tau$ adjustment time scale. Of course, this adjustment only occurs in unstable columns (with positive work function). This approach cir- cumvents computationally difficult problems of uniqueness, associated with cloud-cloud interactions in the original Arakawa-Schubert scheme. Note that both the simplified ArakawaSchubert scheme by Numaguti et al. (1995) and the relaxed Arakawa-Schubert scheme by Moorthi and Suarez (1992) assume two major simplifications in common from the original Arakawa-Schubert scheme: using a linear increase of cumulus vertical mass flux (instead of an exponential function as in the ArakawaSchubert scheme) and the relaxation of cloud work function toward the quasi-equilibrium state over the specified time scale. The adjustment time scale $\tau$ in this study is currently set to 4800 seconds and $\Delta t$ is 1200 seconds. The current scheme also contains a parameterization of downdraft and the evaporation of rain.

In some experiments (SAS/Tok, section 3.2), we introduced a minimum or 'critical' entrainment rate, following Tokioka et al. (1988). The minimum value of $\mu$ is defined as

$$
\mu_{\min }=\frac{\alpha}{D},
$$

where $D$ is the depth of the planetary boundary layer (PBL) and $\alpha$ is a non-negative constant. Only convective plumes of $\mu \geq \mu_{\text {min }}$ are permitted in the cumulus ensemble.

To examine the sensitivity to the cumulus convection scheme, we replaced the standard parameterization with the Kuo (1974) or the MCA (Manabe et al. 1965) scheme. The Kuo parameterization relates cumulus effects on the large-scale temperature and moisture to the column integral of large-scale moisture convergence. In the model, it assumes a fraction $b$ of total moisture convergence is available to moisten the atmosphere, while remaining $(1-b)$ condenses and rains out. The parameter $b$ is related to $R H$, the large-scale column-mean relative humidity (precipitable water divided by saturation value) as

$$
b=1-\frac{R H-R H_{0}}{R H_{1}-R H_{0}},
$$

with values truncated in $[0,1]$. Here $R H_{0}$ and $R H_{1}$ are set to 0.8 and 0.9 , respectively. In words, when the grid mean $R H$ exceeds 0.9 , all converged moisture condenses and rains out, while for $R H<0.8$, no rain occurs and converged moisture simply moistens the column. 
In the MCA scheme, an adjustment process involving two contiguous levels occurs when the layer becomes moist convective unstable and saturated (actually, 99\% of saturation in the current implementation). In that case, the lapse rate is restored to moist adiabatic and excess moisture is assumed to fall out as rain.

\subsection{Experimental design}

For reasons discussed in the introduction, aqua-planet simulations were conducted, in which the surface is entirely covered by water. The same sea surface temperature (SST) distribution were prescribed to be zonally uniform and symmetric about the equator, using Southern Hemisphere observed climatology (Fig. 1a). Sea ice fraction was prescribed where the SST is under the freezing temperature with a cosine function maximum at the poles. These distributions of SST and sea ice are identical to those of Lee et al. (2001). The zonally uniform radiative cooling rate was also prescribed, as in Chao and
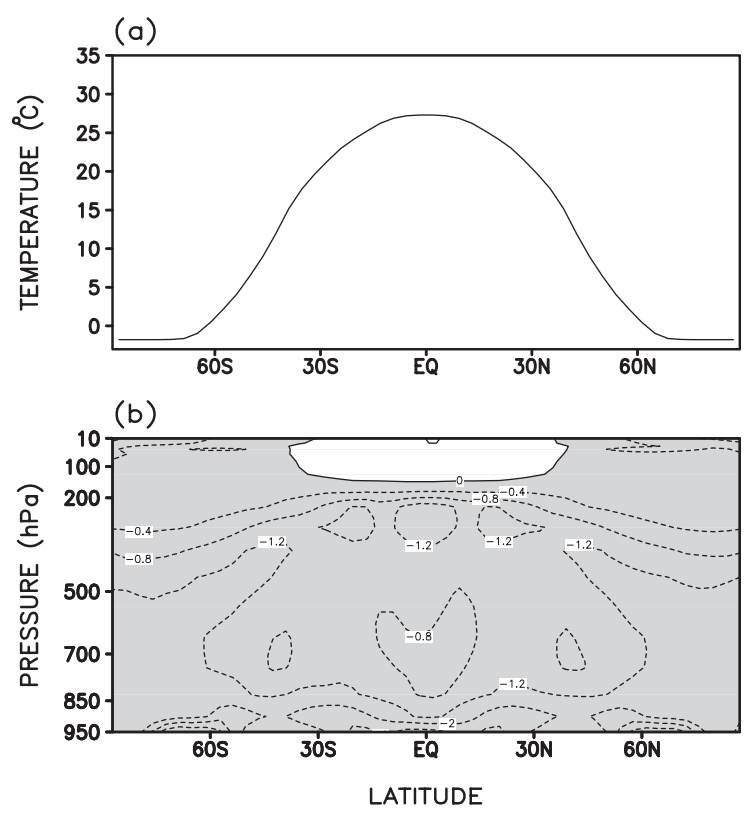

Fig. 1. (a) Latitudinal distribution of prescribed sea surface temperature $\left({ }^{\circ} \mathrm{C}\right)$ which is zonally uniform and symmetric about the equator, and (b) latitudeheight vertical distribution of zonally uniform radiative heating rate $\left(\mathrm{K} \mathrm{day}^{-1}\right)$ prescribed in the aqua-planet perpetual simulation. Negative values are shaded and contoured with dashed lines in (b).
Deng (1998). The averaged heating rate was used from three initial aqua-planet runs, with interactive radiation and each of the different cumulus schemes in turn. Figure $1 b$ shows the latitude-vertical distribution of this composite radiative cooling rate. This same radiative cooling rate was applied to all experiments analyzed in this paper. No diurnal cycle is included. For discussion purposes, the aqua-planet run with the simplified Arakawa-Schubert scheme is indicated in the figures by SAS, the same SAS run but with $\alpha=0.1$ in equation (4) is indicated by SAS/Tok, the Kuo run by KUO, and the moist convective adjustment run by MCA. All of them were started from the same initial condition taken from an arbitrary state of the model and integrated for 120 days. The change of initial condition did not affect the obtained results qualitatively after 30 days integration, so the initial 30 days outputs are discarded as an adjustment period.

The influences of SAS modification of cumulus entrainment rate under realistic terrestrial lower boundary conditions were examined in section 6. Two AGCM integrations, with and without SAS modification, were conducted for more than two years (January 1996-August 1998), driven by the observed weekly SST from the National Center for Environmental Prediction (NCEP). Obtained precipitation and velocity potential fields are compared to the Global Precipitation Climatology Project (GPCP) onedegree daily (1DD) precipitation data (Huffman et al. 2001), and NCEP/NCAR reanalysis data (Kalnay et al. 1996) as observations.

\section{Variability and climatology with the various schemes}

\subsection{Standard implementations}

The ISO dependence on the cumulus schemes is investigated by examining the characteristics of equatorial disturbances simulated in each aqua-planet experiment. Figure 2 shows longitude-time diagrams of precipitation rate at the equator $\left(5^{\circ} \mathrm{S}-5^{\circ} \mathrm{N}\right)$ for $31-120$ days. In SAS (Fig. 2a), precipitation appears in patches with small values, while streaks of more intense and organized precipitation occur in KUO (Fig. 2b) and MCA (Fig. 2c), resembling observed equatorial moist Kelvin waves (Wheeler and Kiladis 1999). The upper-level velocity potentials at $200 \mathrm{hPa}$ are shown in Fig. 3 to represent the 

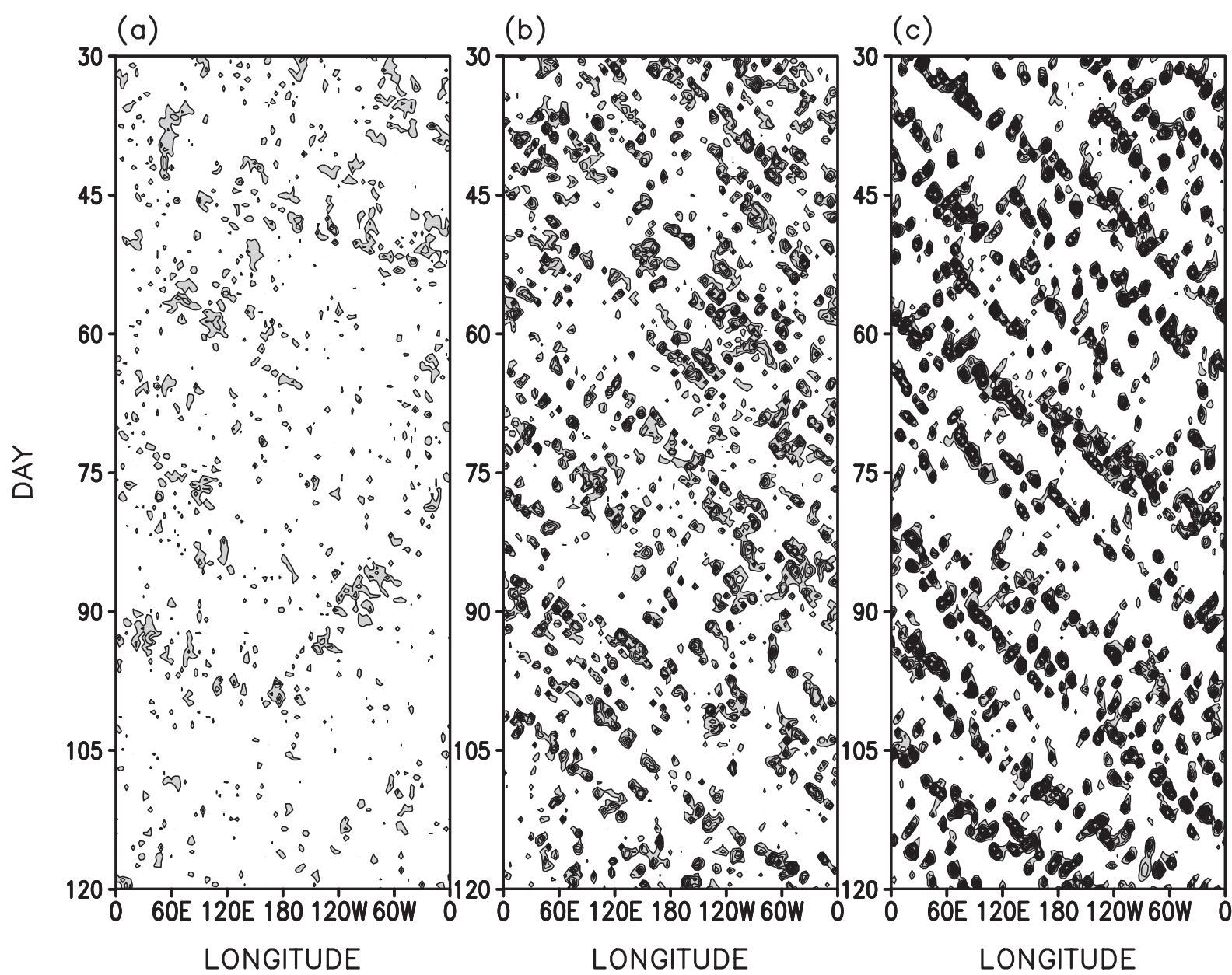

Fig. 2. Longitude-time diagrams of precipitation rates $\left(\mathrm{mm} \mathrm{day}^{-1}\right)$ averaged between $5^{\circ} \mathrm{S}-5^{\circ} \mathrm{N}$ obtained from (a) SAS, (b) KUO, and (c) MCA. SAS indicates the aqua-planet experiment with the simplified Arakawa-Schubert scheme, KUO with the Kuo scheme, and MCA with the moist convective adjustment scheme. Precipitation rate is sampled twice a day and averaged for 12 hours. More than $7 \mathrm{~mm} \mathrm{day}^{-1}$ are shaded.

large-scale divergent circulation features associated with the convective disturbances. As in the precipitation patterns, the magnitude of upper-level divergent flow in SAS (Fig. 3a) is much weaker, and the eastward wave propagation is less clear, compared with the KUO (Fig. 3b) and MCA (Fig. 3c) cases. KUO and MCA runs feature around-the-globe periods of 30 days ( $15 \mathrm{~m} \mathrm{~s}^{-1}$ propagation speed), with zonal wavenumber 1-2 components most prominent. The MCA scheme produces the largest ISO variability among the three tested schemes, and SAS the smallest, consistent with the findings of Chao and Deng (1998).
Although the MCA scheme produces the largest ISO variability and clear eastward propagations of convection region, it shows somewhat distinguished feature from the real observed convection, despite the horizontal resolution of the model ( $\sim$ few hundred kilometers grid mesh in T31 truncation) is much restricted to resolve the fine structure of observed cloud clusters. In fact, real convection does exhibit the planetary-scale wavenumber 1 packet of the ISO, within which hierarchical sub-structures of eastward-moving super clusters (horizontal scale of several thousand kilometers) and westward-moving cloud clusters 
(a)

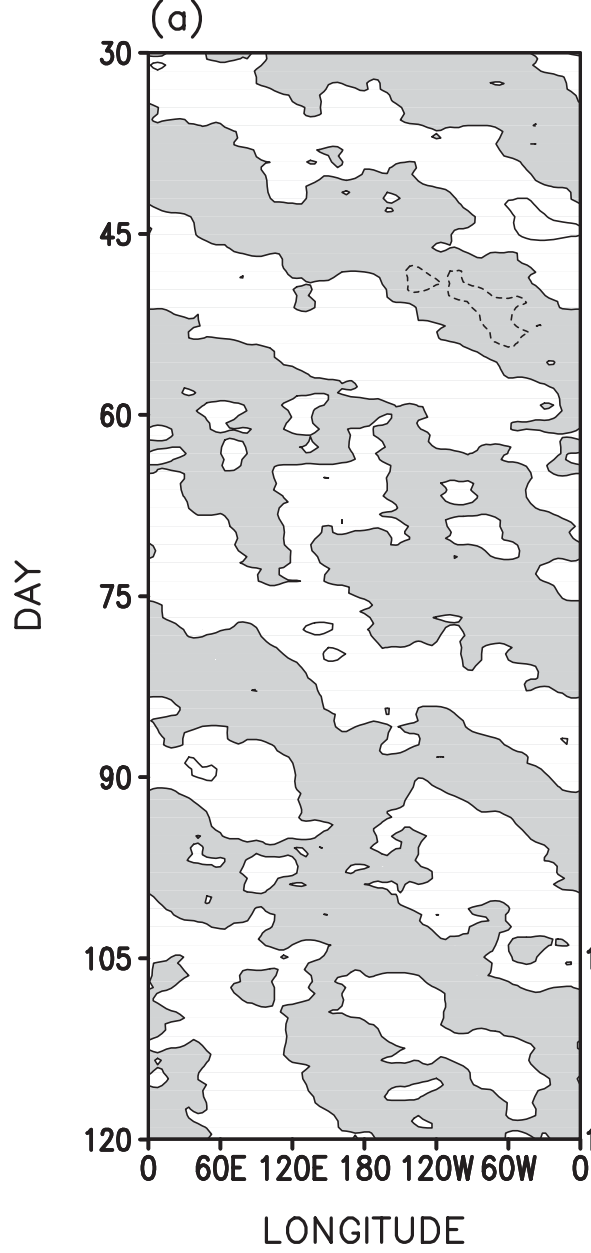

(b)

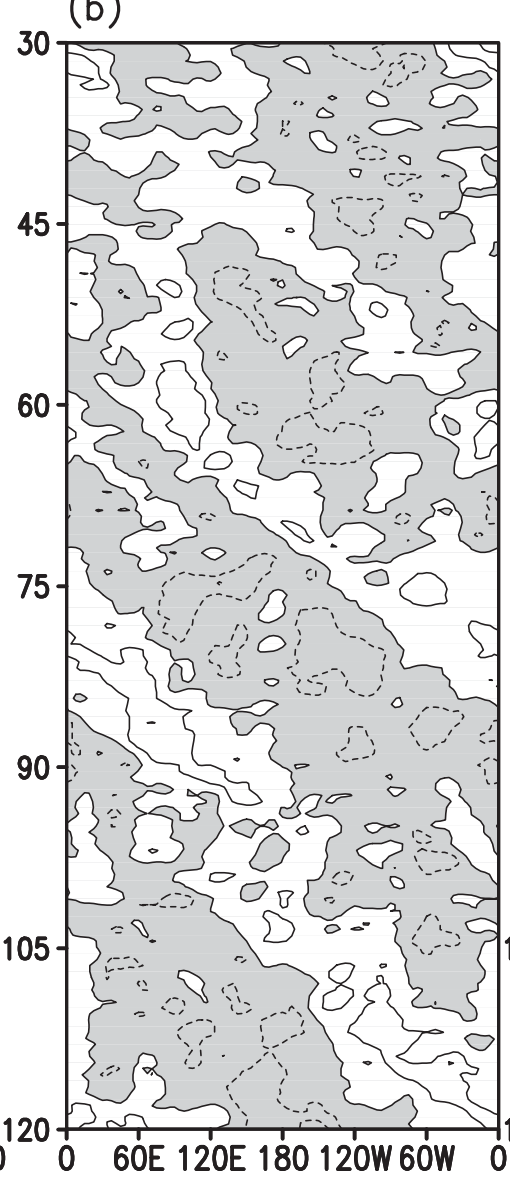

LONGITUDE (c)

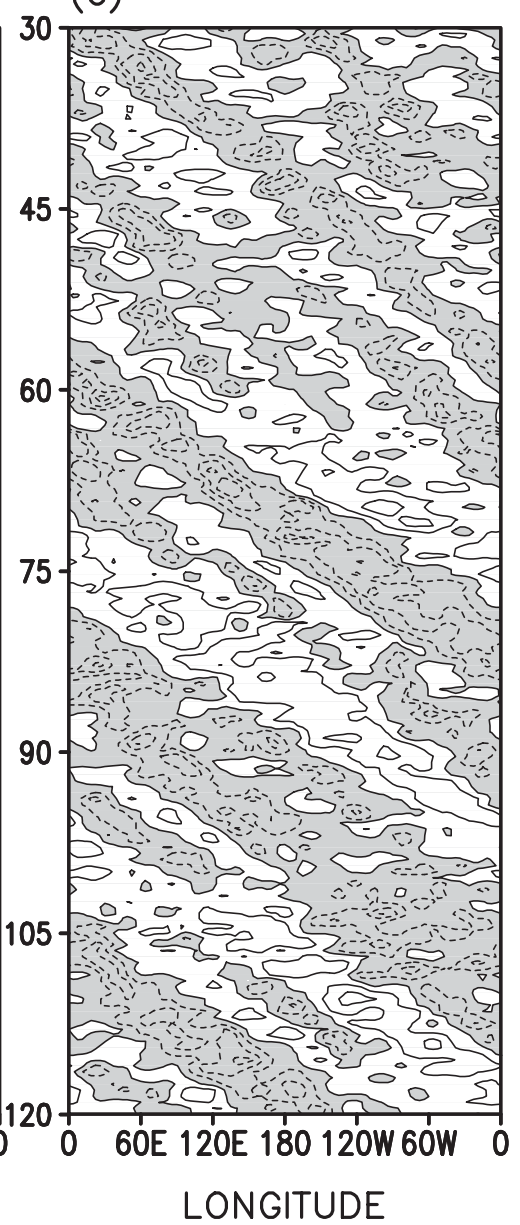

Fig. 3. Same as Fig. 2 except for the $200 \mathrm{hPa}$ velocity potential $\left(\mathrm{m}^{2} \mathrm{~s}^{-1}\right)$ averaged between $10^{\circ} \mathrm{S}-$ $10^{\circ} \mathrm{N}$. The contour intervals are $1 \times 10^{6} \mathrm{~m}^{2} \mathrm{~s}^{-1}$, and negative values are shaded and contoured with dashed lines. No spatial or temporal filter is applied to the velocity potential field.

(several hundred kilometers) are embedded (Nakazawa 1988). Organizations of super clusters within planetary scale ISO packet are not well reproduced due to the intense and localized bursts of small-scale convections in the MCA case (Fig. 2c).

Numaguti and Hayashi (2000) found that the temporal evolution of simulated super cloud clusters associated with ISO variability were very similar in experimental model runs with and without the MCA scheme. A similar experiment was conducted, without any deep convection parameterization, and the results were not much different from the MCA case (not shown). Perhaps this is not too surprising, as the MCA scheme only acts when the model achieves saturation in conditionally unstable regions-the conditions in which model dynamics would begin to produce explicit moist convection at resolved scales. In practice, the MCA scheme and resolved condensation are both active, and contribute about equally to condensation heating (Fig. 12 below).

The zonal mean state also varies considerably among the simulations. Figure 4 shows zonal mean distributions of precipitation rate (Fig. 4a), and surface evaporation (Fig. 4b) averaged over 61-120 days. A double Intertropical Convergence Zone (ITCZ) structure appears in SAS and KUO simulations, straddling the equator at $10^{\circ} \mathrm{S}$ and $10^{\circ} \mathrm{N}$. Hess et al. (1993) showed that the double ITCZ climatology in 

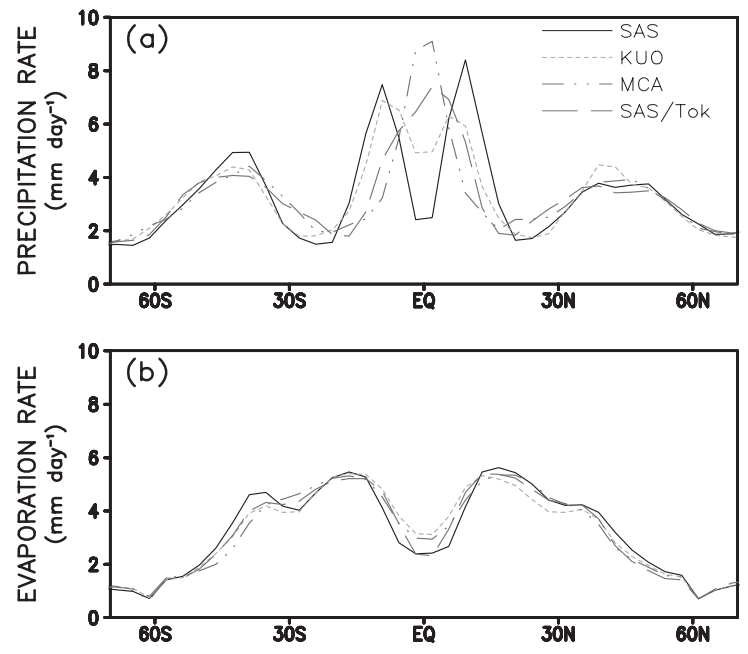

Fig. 4. Zonal mean distributions of (a) precipitation rate, and (b) surface evaporation rate averaged for $61-120$ days, obtained from SAS (solid line), KUO (dotted), MCA (double dotted and dashed), and SAS/Tok (dashed). SAS/ Tok indicates the aqua-planet experiment with the modified SAS scheme by the cumulus minimum entrainment rate constraint, in which the coefficient $\alpha$ in equation (4) is set to 0.1 . The unit is mm day ${ }^{-1}$.

their runs with the Kuo scheme could be traced to the time-mean effect of mixed Rossby-gravity waves, favored by the scheme's moistureconvergence closure. On the contrary, MCA simulates a single strong narrow rainfall zone at the equator. In surface evaporation (Fig. 4b), there seems little difference among the three cases. Each simulation shows an equatorial minimum straddled by symmetric maxima around $15^{\circ} \mathrm{S}$ and $15^{\circ} \mathrm{N}$. Strong rainfall in the equatorial region in MCA therefore indicates strong tropical meridional moisture transport toward the equator, whether by the mean Hadley circulation or by zonally asymmetric waves. The KUO curve shows in-between features of the two other schemes in the equatorial rainfall amount.

Other aqua-planet experiments with different models also simulate similar results as in our study-the Arakawa-Schubert scheme or its variants, and the Kuo scheme frequently make double ITCZ (Hayashi and Sumi 1986;
Swinbank et al. 1988; Hess et al. 1993; Chao and Deng 1998), whereas the MCA makes single (Hess et al. 1993; Chao and Deng 1998). We have checked that these different ITCZ structures are insensitive to the initial state of the model, which illustrates that the model ITCZ structure depends on the physical nature of deep convection parameterization.

The SAS scheme makes very weak transient activity in the equatorial region, which may be suspected to be related to the weak zonal mean rainfall there. We further investigated the transient responses in the off-equatorial region, with longitude-time cross sections of precipitation rates and $200 \mathrm{hPa}$ velocity potentials averaged between $5^{\circ}-15^{\circ} \mathrm{N}$ latitude belts (Fig. $5)$. This area covers the northern rainfall maximum located around $10^{\circ} \mathrm{N}$ in SAS and KUO. The transient characteristics appeared in precipitation rates (Fig. 5a) are slightly different from those of the equatorial region (Fig. 2), with westward-moving rain streaks seen in both SAS and KUO cases. These small-scale westward-moving storms appear to lie within eastward-moving envelopes of a larger horizontal scale, considered with the temporal evolutions of upper-level velocity potentials (Fig. 5b; almost same as Fig. 3 due to its large-scale structure). This pattern resembles the observed hierarchical movement structure of cloud clusters indicated by Nakazawa (1988). The westward moving small-scale storms are not clearly observed in the MCA run (Fig. 5a), instead eastward-moving transients still seem to dominate, as in the equatorial region. These results will be revisited with spectral analysis in section 3.3 .

\subsection{SAS with minimum entrainment threshold}

In the previous results, SAS makes weak convective variability in the tropics, and it was hypothesized that more stringent criteria for the occurrence of deep convection would increase variability. Following Tokioka et al. (1988), we modified the SAS scheme to enforce a minimum entrainment rate in convective plumes, as described in section 2.2, equation (4). A free parameter $\alpha$ determines this minimum entrainment rate (inversely proportional to the radius of a convective plume), as a function of PBL depth. 
(a) PRECIPITATION RATE
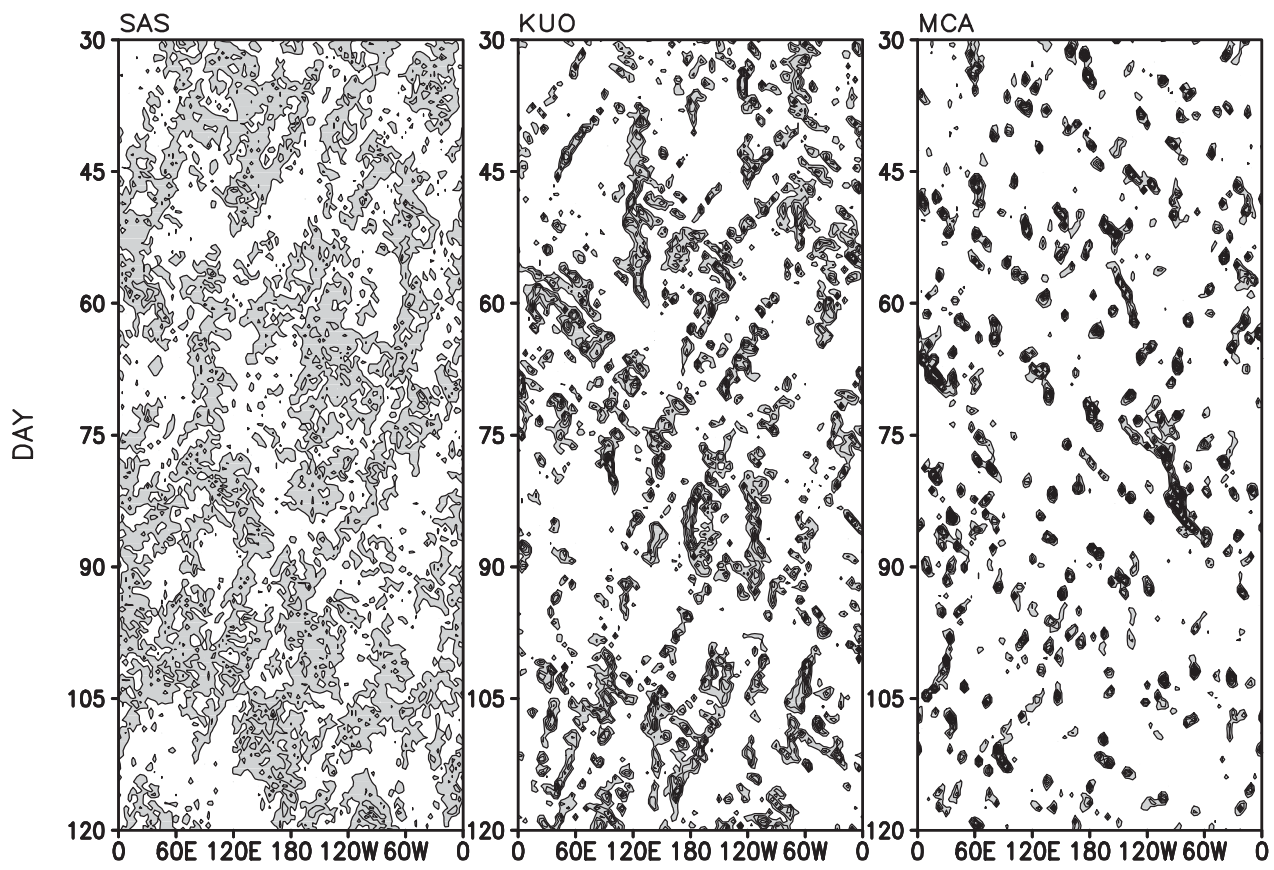

(b) VELOCITY POTENTIAL
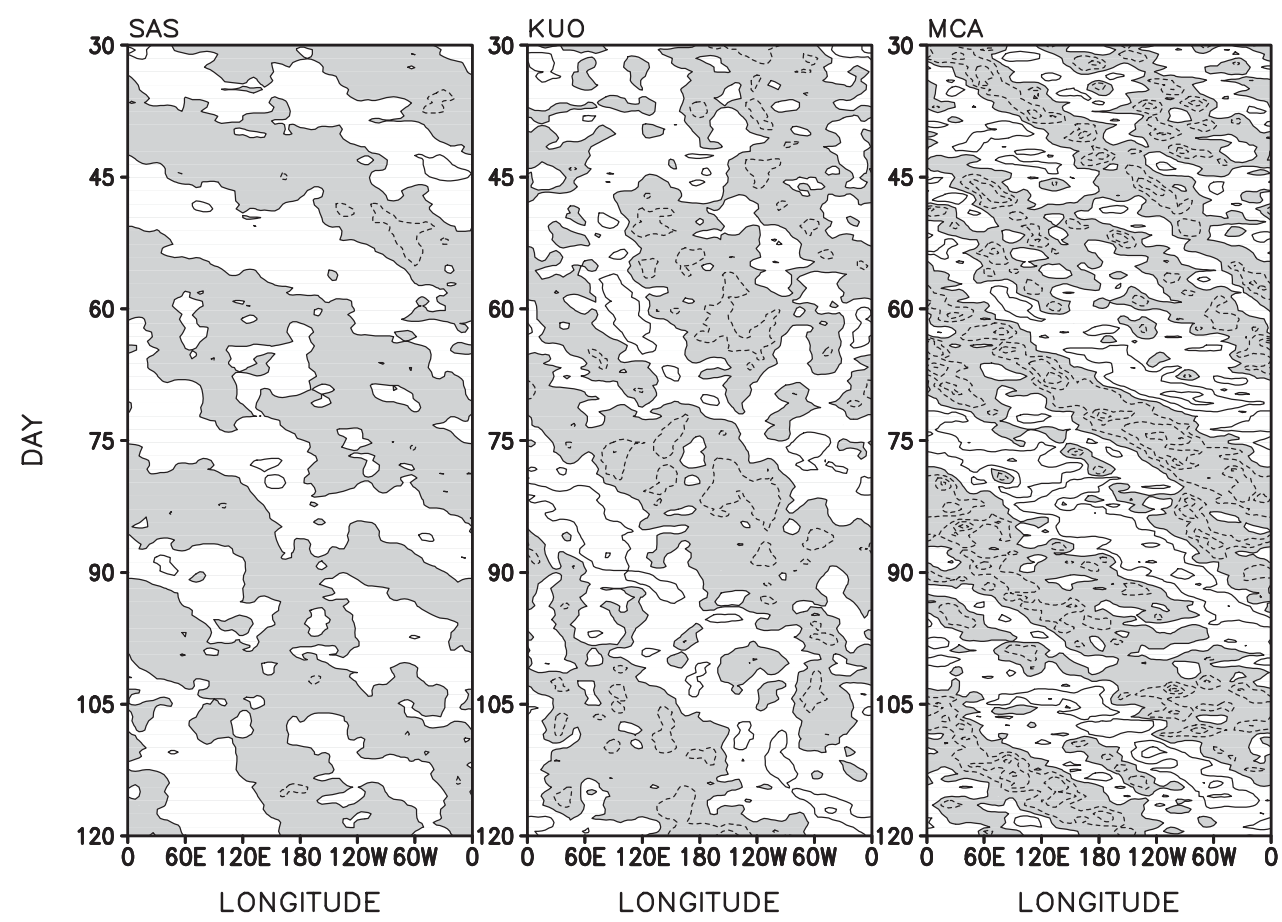

Fig. 5. Longitude-time diagrams of (a) precipitation rates $\left(\mathrm{mm} \mathrm{day}^{-1}\right)$ and (b) $200 \mathrm{hPa}$ velocity potential $\left(\mathrm{m}^{2} \mathrm{~s}^{-1}\right)$ averaged between $5^{\circ}-15^{\circ} \mathrm{N}$, obtained from the three aqua-planet experiments. The contour intervals and shadings of (a) and (b) are same as in Fig. 2 and Fig. 3, respectively. 


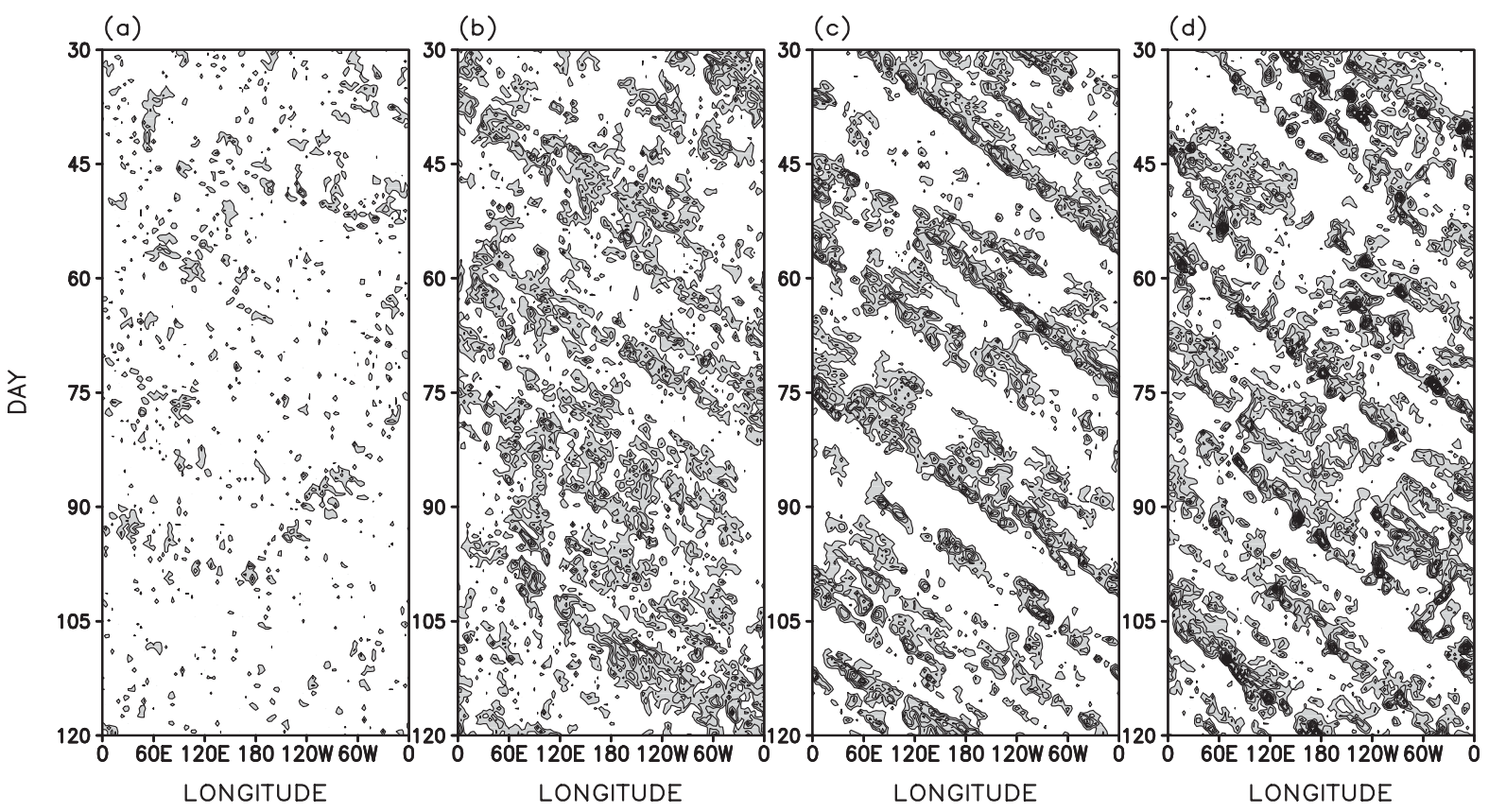

Fig. 6. Longitude-time diagrams of precipitation rates $\left(\mathrm{mm} \mathrm{day}^{-1}\right)$ averaged between $5^{\circ} \mathrm{S}-5^{\circ} \mathrm{N}$ when the coefficient $\alpha$ in the cumulus minimum entrainment rate is set to (a) 0.0 , (b) 0.05 , (c) 0.15 , and (d) 0.25 . The contour intervals are $7 \mathrm{~mm} \mathrm{day}^{-1}$, and more than $7 \mathrm{~mm} \mathrm{day}{ }^{-1}$ are shaded.

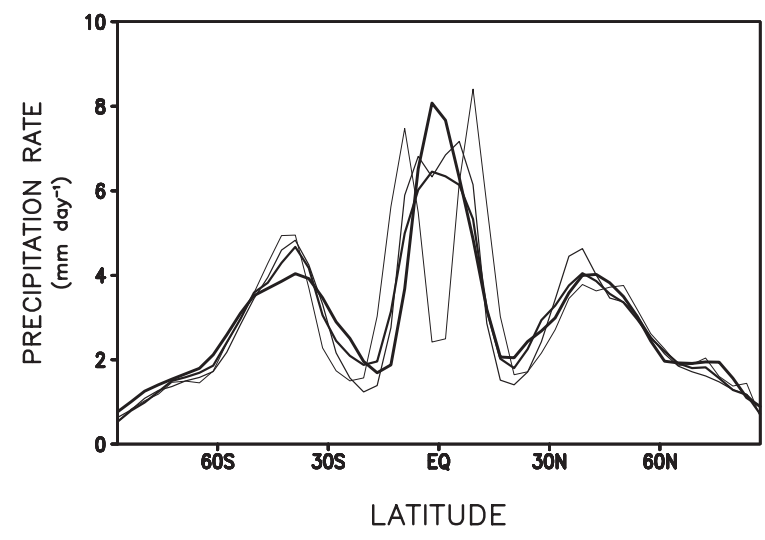

Fig. 7. Zonal mean distributions of precipitation rate when the coefficient $\alpha$ in the cumulus minimum entrainment rate is set to $0.0,0.05,0.15$, and 0.25 in SAS/Tok. The thicker line represents larger $\alpha$.

Figure 6 shows the sensitivity of equatorial transients to $\alpha$, in longitude-time diagrams of precipitation rates averaged over $5^{\circ} \mathrm{S}-5^{\circ} \mathrm{N}$. The intensity of transients in the precipitation pat- terns increases monotonically as $\alpha$ is changed from zero to $0.05,0.15$ and 0.25 , as seen in stronger contrasts between relatively dry regions, and areas of intense rainfall. Eastward propagation of features is prominent, with the almost same propagation speed $\left(\sim 15 \mathrm{~m} \mathrm{~s}^{-1}\right.$, a 30 day around-the-globe period) for all values of $\alpha$. The total rainfall in this equatorial belt also increases drastically as $\alpha$ is increased above 0 , as shown more clearly in Fig. 7. The widelyspaced double ITCZ of the standard SAS case quickly gives way to a narrow convection zone on the equator, which is essentially the same for all nonzero values of $\alpha$. The results of Figs. 6-7 demonstrate that the zonal-mean climatology and transient disturbances are much related. As the mean convection becomes more concentrated on the equator, transient disturbances are apparently increasing subject to organization by Kelvin waves. This will be discussed further below.

For all further analyses, the designator 'SAS/ Tok' will refer to the case $\alpha=0.1$, shown in Fig. 8. Longitude-time cross-sections of precipitation rates $\left(5^{\circ} \mathrm{S}-5^{\circ} \mathrm{N}\right)$, eddy (zonal mean re- 

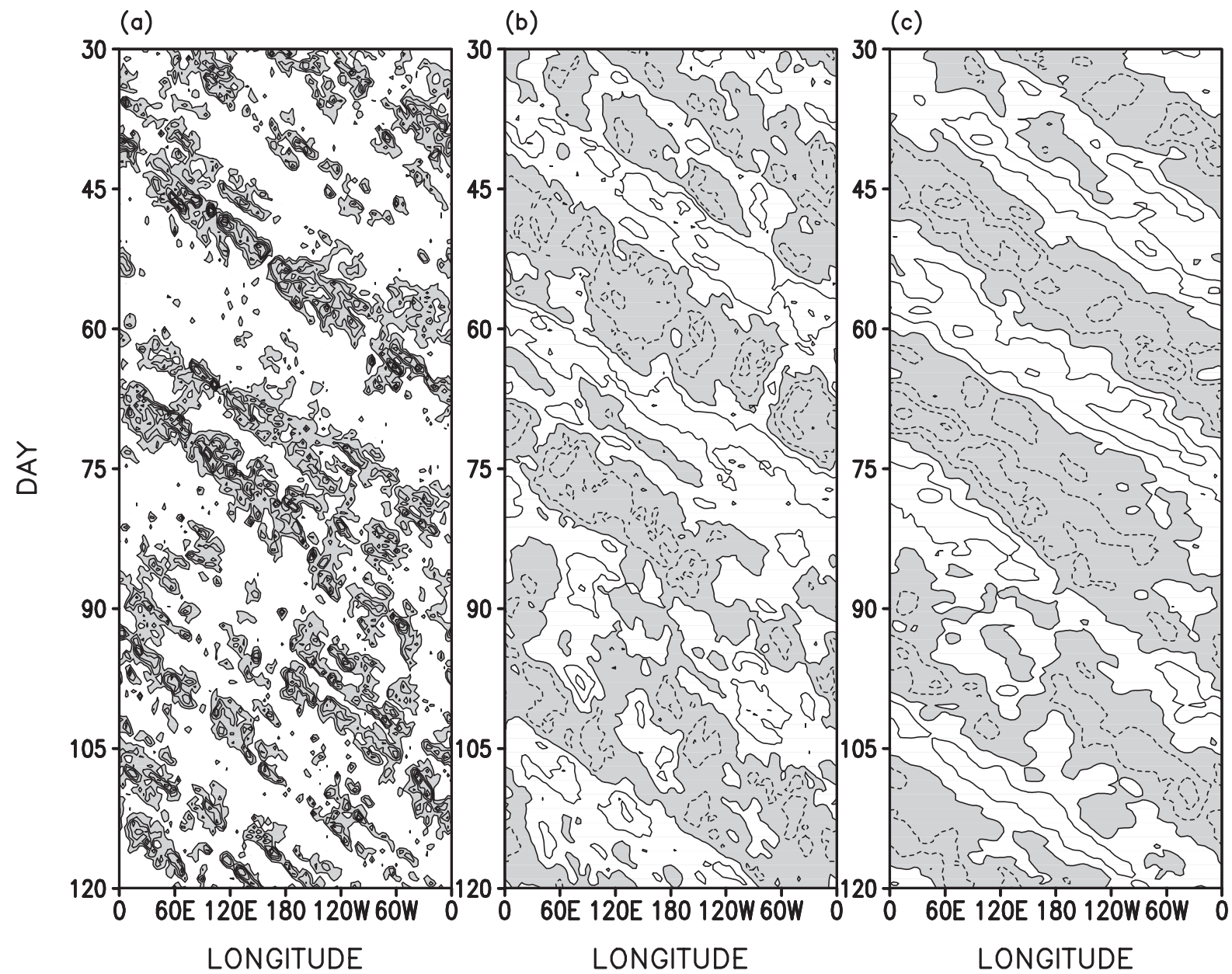

Fig. 8. Longitude-time diagrams of (a) precipitation rates $\left(5^{\circ} \mathrm{S}-5^{\circ} \mathrm{N}\right)$, (b) $200 \mathrm{hPa} u$-wind $\left(10^{\circ} \mathrm{S}-\right.$ $\left.10^{\circ} \mathrm{N}\right)$, and (c) $200 \mathrm{hPa}$ velocity potential $\left(10^{\circ} \mathrm{S}-10^{\circ} \mathrm{N}\right)$ for the SAS/Tok case $(\alpha=0.1)$. In (b), zonal mean is removed. The contour intervals are $7 \mathrm{~mm} \mathrm{day}^{-1}$ in (a), $10 \mathrm{~m} \mathrm{~s}^{-1}$ in (b), and $10^{7} \mathrm{~m}^{2} \mathrm{~s}^{-1}$ in (c). More than $7 \mathrm{~mm} \mathrm{day}^{-1}$ are shaded in (a), and negative values are shaded and contoured with dashed lines in (b) and (c).

moved) $u$-winds $\left(10^{\circ} \mathrm{S}-10^{\circ} \mathrm{N}\right)$, and velocity potentials at $200 \mathrm{hPa}\left(10^{\circ} \mathrm{S}-10^{\circ} \mathrm{N}\right)$ show clear eastward propagating waves, with about 30day period and prominent contribution by zonal wavenumber 1 . Comparing SAS/Tok with SAS (Fig. 2a and Fig. 3a), the precipitation intensity, and the magnitude of upper-level velocity potential variability, are much enhanced.

\subsection{Space-time spectral analysis}

Characteristic scales and periods of propagating signals in the simulated precipitation field were investigated using space-time power spectrum analysis (Hayashi 1982) of precipitation rate during days $31-120$, over the tropical regions $20^{\circ} \mathrm{S}-20^{\circ} \mathrm{N}$. Precipitation rate is sampled twice a day, so that the time series has 180 time points. Following Wheeler and Kiladis (1999), the symmetric and asymmetric components about the equator are constructed from the total precipitation field, and time-longitude sections of each component are spectrally analyzed. Figure 9 shows contour plots of the resulting symmetric (left), and asymmetric (right) power spectra. The spectra are noisy, owing to the short time series, but adequate for the following discussion.

Not surprisingly, SAS shows the weakest power in both components (a smaller contour interval is used in Fig. 9a to avoid blank plots). 

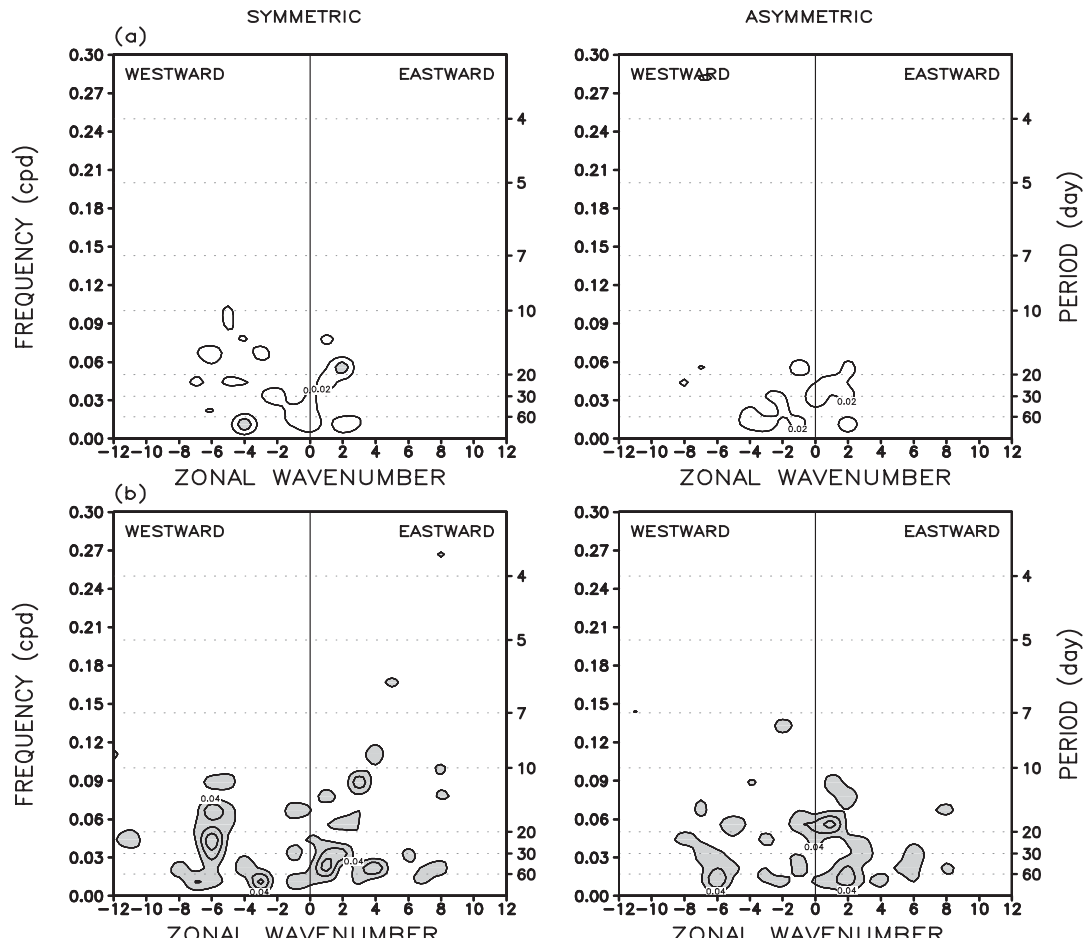

ZONAL WAVENUMBER
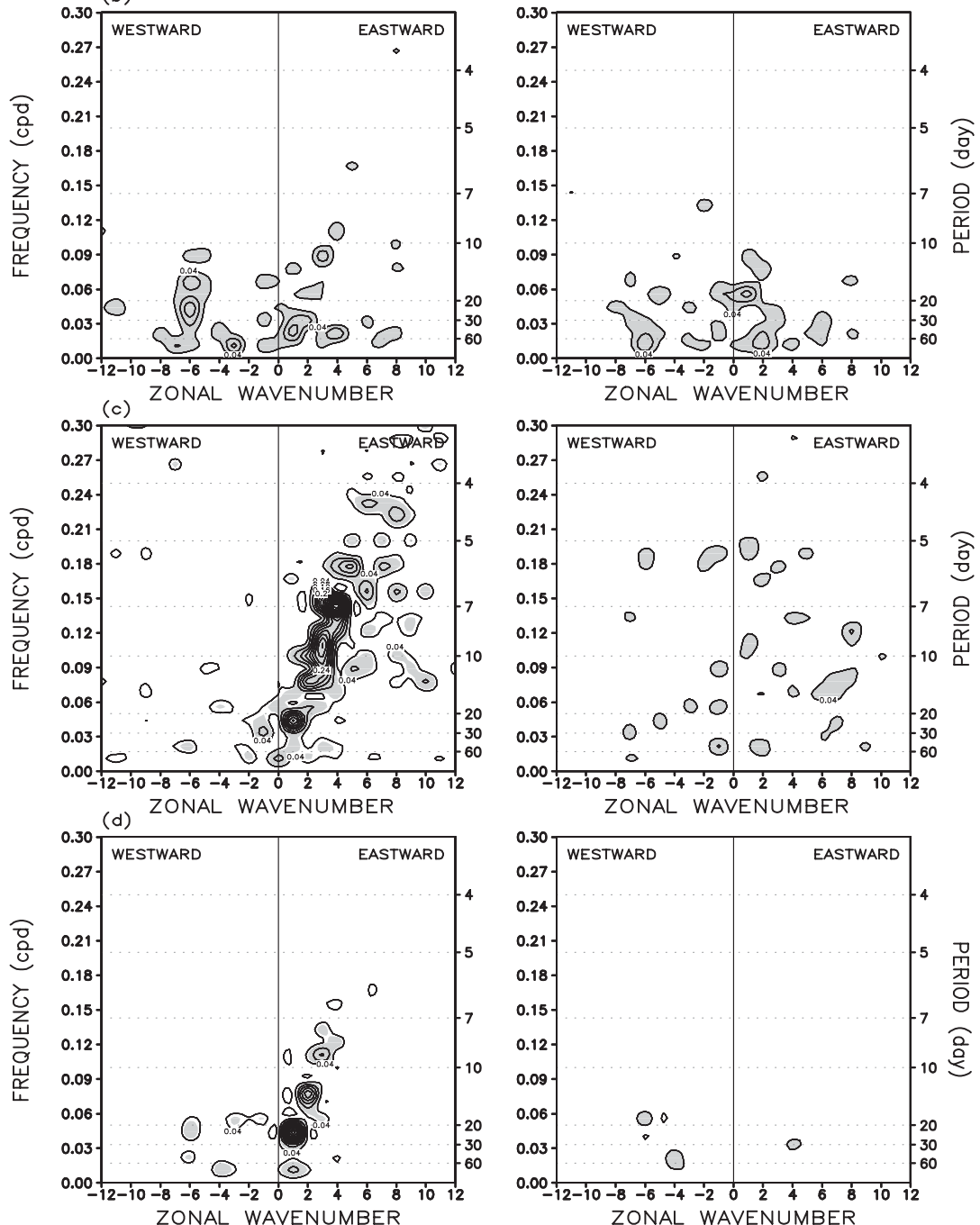

Fig. 9. Space-time power spectra of precipitation rate for the (a) SAS, (b) KUO, (c) MCA, and (d) SAS/Tok cases. Symmetric components about the equator (left) and asymmetric components (right) are separately drawn, using twice daily, 12-hour averaged precipitation rates. The power has been summed over $20^{\circ} \mathrm{S}-20^{\circ} \mathrm{N}$. The unit is $\left(\mathrm{mm} \mathrm{day}^{-1}\right)^{2}$ and the contour interval is 0.04 except 0.02 for (a). More than 0.04 are shaded in each figure. 
The largest SAS variance, of dubious significance, is in the eastward moving symmetric wave with zonal wavenumber 2 , and 20-day period. Spectral variances in KUO (Fig. 9b) are much stronger than SAS over the whole spectrum of both symmetric and asymmetric parts. In the symmetric eastward variances, moist Kelvin wave structure can be found, resembling the observed linear dispersion relation between wavenumber and frequency (Wheeler and Kiladis 1999), with the zonal wavenumber 1 component dominant. Westward-moving power at zonal wavenumbers $6-7$ is also prominent, with comparable symmetric and asymmetric power, as would be seen for disturbances confined to one hemisphere. We suppose these to be storms advected by background zonal winds in the middle and lower troposphere (Lee et al. 2001).

The MCA spectrum (Fig. 9c) shows the most distinct spectral characteristics, dominated by Kelvin waves featuring symmetric, eastward, and with a straight linear dispersion relation implied by the power contours. Zonal wavenumber 1 is prominent, but strong contributions are also seen in wavenumbers up to $4-5$. The SAS/Tok run (Fig. 9d) is also dominated by symmetric variance lying along a Kelvin dispersion line. The KUO run has the most asymmetric power of all the runs, even more than MCA, despite MCA's much larger total variance. Presumably this is related to the fact that the KUO rainfall climatology has more rain off the equator in double ITCZs (Hess et al. 1993).

\section{Vertical structure}

To provide material for deeper understanding of the different performances of the schemes, this section examines vertical structure, including the different mean stratifications, ISOmodulated heating profiles in the various runs, and the composite vertical structure of the ISO in the SAS/Tok run. The line of inquiry is not entirely direct, but leads into the discussion in section 7 .

\subsection{Thermodynamic state profiles}

Figure 10 shows the composite vertical profiles of moist static energy-defined as $M \equiv$ $C_{p} T+g z+L q$, where $T, z$, and $q$ are temperature, geopotential height, and specific humidity, respectively, and $C_{p}$ specific heat of dry air at constant pressure, $g$ gravity acceleration, and $L$ latent heat of condensation-in rainy (precipitation rate $>2 \mathrm{~mm} \mathrm{day}^{-1}$ ) and dry (the rest) regions, for each scheme. The whole tropical region, between $20^{\circ} \mathrm{S}-20^{\circ} \mathrm{N}$, is chosen because the equatorial convergence zones are located differently among the simulations. A mid-troposphere minimum is evident in all cases, as is typical of the tropics. In Fig. 10c, the differences are given by subtracting the dry profile from the rainy. All simulations show positive differences from the surface up to the $200 \mathrm{hPa}$ level, indicating primarily more humidity in rainy areas. However, the magnitude of this difference differs widely, particularly in the lower troposphere.

The rainy-dry $M$ difference is small in SAS, because even rainy areas are very dry at low levels (Fig. 10a). Penetrative plumes of convection tend to dry the mean state in the lower troposphere, to which their occurrence is not very sensitive because nearly-undiluted plumes are permitted. The downdraft and rain reevaporation parameterizations help reduce this drying (discussed for example in Maloney and Hartmann 2001), but SAS still has the driest mean state among the runs shown. With the minimum entrainment rate, SAS/Tok requires more humid environments to produce rain (Fig. 10a), but this changes only slightly the humidity in the dry category (Fig. 10b).

Note also that $M$ in the upper troposphere decreases from SAS to SAS/Tok. At these high altitudes, the $M$ difference indicates mainly temperature difference. In the plume model of the Arakawa-Schubert scheme, the cloud top is characterized by the entrainment rate. The plumes with large entrainment cannot reach upper levels, and this can make upper level temperature reduction. Imagining a sudden change from SAS to SAS/Tok, the ambient temperature at upper levels would cool until the more dilute updrafts became sufficiently buoyant in the new climate to penetrate and heat the upper troposphere, achieving radiativeconvective climate balance at a new, lower temperature. This simple line of argument is complicated somewhat by the existence of a large-scale condensation scheme that shares the duty of heating the upper troposphere (Fig. 12, discussed below), but still seems a useful way of thinking.

The rainy-dry humidity difference is largest 

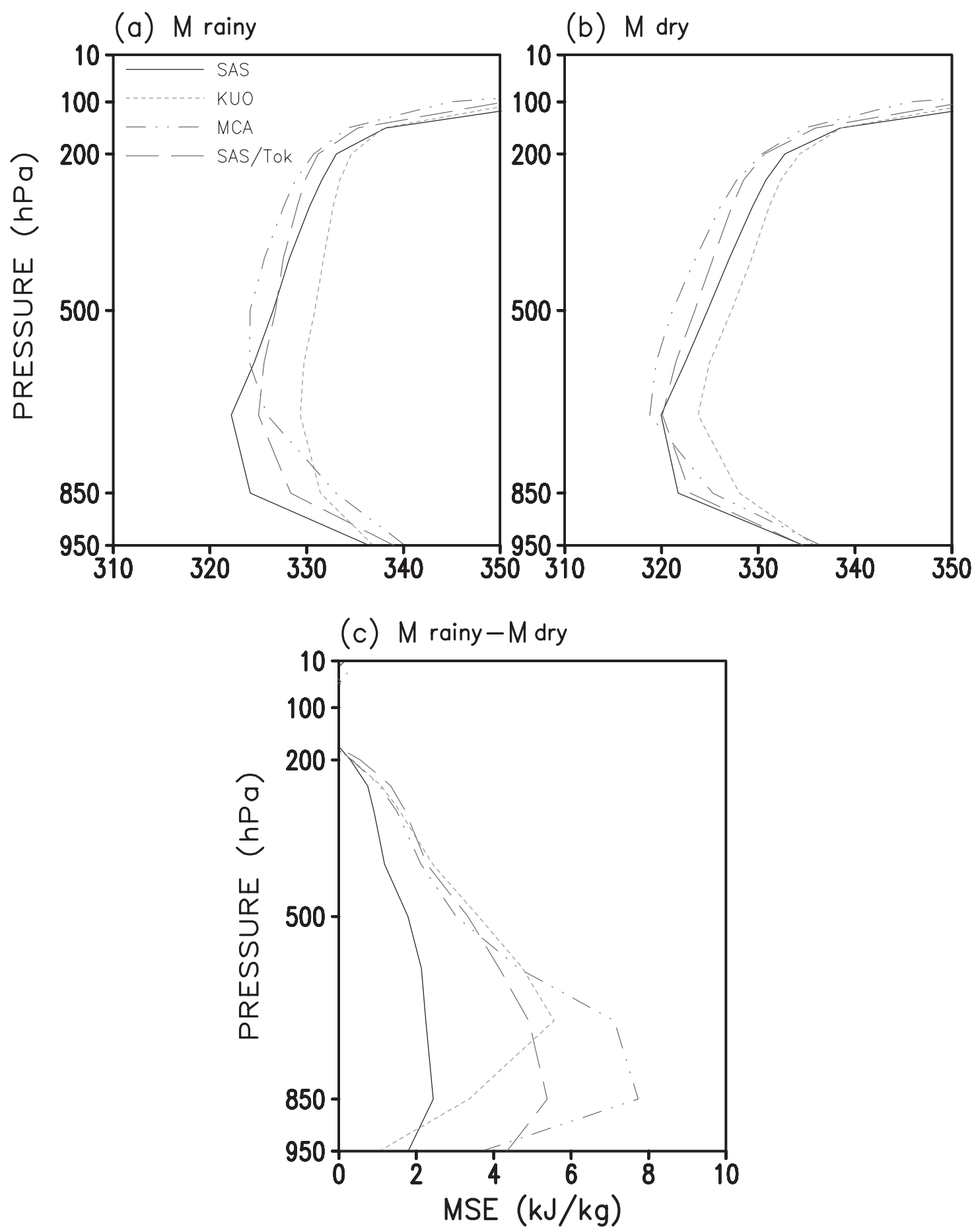

Fig. 10. Vertical distributions of moist static energy $(M)$ for (a) rainy (precipitation rate$>2 \mathrm{~mm} \mathrm{day}^{-1}$ ), and (b) dry (the rest) regions within $20^{\circ} \mathrm{S}-20^{\circ} \mathrm{N}$ latitude belts. (c) is obtained by subtracting (b) from (a). 
in the MCA run (Fig. 10c), and the upper troposphere is the coldest among the runs, because MCA is essentially a strongly entraining form of convection. It occurs only where the air becomes saturated at grid scale, and develops upward through a complete mixing process (homogenization of moist static energy), between every pair of levels. As a result, a very cold upper troposphere must develop to achieve balance with this highly diluted convective heating process. The KUO run has a relatively warm upper troposphere, as it consults an undiluted parcel buoyancy to decide the height of convection. The lower troposphere is moist in KUO, determined by the specified $80-90 \%$ target range specified in equation (5) for columnaveraged relative humidity.

\subsection{Heating profiles}

The vertical profile of diabatic heating has been hypothesized to be important in the simulation of the ISO, as discussed in the introduction. Figure 11 shows profiles of the ISOvarying heating (hereafter simply called the

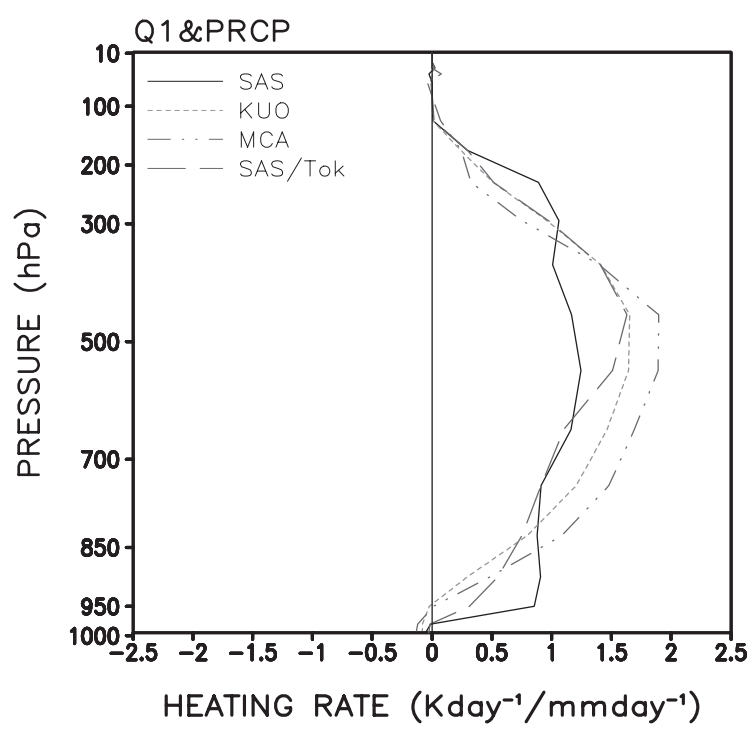

Fig. 11. Vertical profiles of anomalous total diabatic heating rate associated with the intraseasonal variability, which is calculated by the regression of total diabatic heating rate at each altitude against intraseasonally filtered (20-60 day) precipitation rates over the $5^{\circ} \mathrm{S}-5^{\circ} \mathrm{N}$ latitude belts. The unit is $\left(\mathrm{K} \mathrm{day}{ }^{-1}\right) /\left(\mathrm{mm} \mathrm{day}{ }^{-1}\right)$. heating profile), calculated as the regression coefficient between total diabatic heating rate at each altitude (labeled Q1 in the figure), and surface precipitation. The precipitation variations are band-pass filtered in time to retain 20-60 day variability. The regression coefficients were calculated over the every grid points within the $5^{\circ} \mathrm{S}-5^{\circ} \mathrm{N}$ latitude belt and then composited. The biggest difference among the heating profiles is that the SAS scheme is something of an outlier, with a square heating profile. SAS has very little 20-60 day precipitation variability available for this regression (Fig. 2a), and its variability is not really predominant in propagating dynamical modes. The other three runs are broadly similar, with anomalous heating peaked in the middle troposphere. All the three are much less topheavy than observed heating variations in the Madden-Julian oscillation, an error common to many models (Lin et al. 2003), despite the SAS/ Tok being most top-heavy among the three.

Dependence of propagation speed on the heating profile is not clearly evident from the data examined. The phase speed of intraseasonal propagating waves varies only a little among these simulations, with the KUO run a bit slower (period of 30-60 days for wavenumber 1 in Fig. 9b), and MCA a bit faster (2030 day period). These differences can also be detected in Figs. 2-3. However, the KUO and MCA runs have almost the same heating profile in Fig. 11. In fact, the vertical structures of total heating in all cases (Fig. 11) are broadly similar in a sense that they have the middleheavy heating profiles in common with maximum around $500 \mathrm{hPa}$ level.

When deep convection is restricted by conditions, large-scale condensation tends to increase to supplement convective heating. The individual contributions of cumulus convection, and large-scale condensation tendencies, again expressed as regression coefficients relating them to 20-60 day filtered precipitation, are given in Fig. 12. The broadly-similar total heating profiles of Fig. 11 are seen to consist of varying combinations of convective, and largescale condensation terms. In the SAS run, intraseasonal variations of large-scale condensation occur only in the highest altitudes of the troposphere. The much more constrained MCA scheme gives a large role to large-scale 

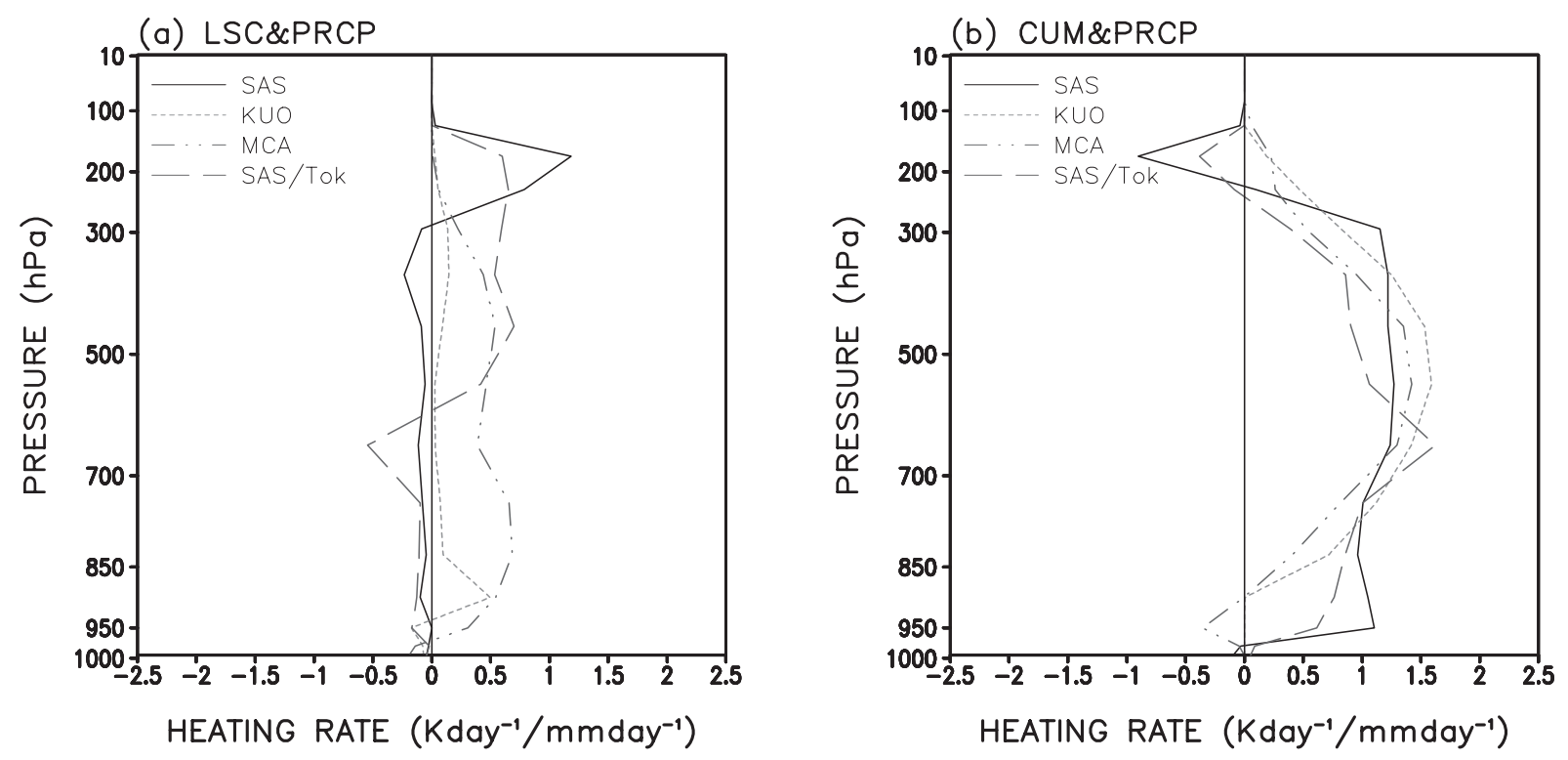

Fig. 12. Same vertical heating profiles as in Fig. 11 except for the regression of (a) large-scale condensational heating rate and (b) cumulus heating rate against filtered precipitation rates.

condensation throughout the lower-middle troposphere. Adding a constraint (SAS/Tok) increases the depth, and the vertical average of large-scale condensation heating in the upper troposphere. In particular, the amplitude becomes larger in the middle troposphere, apparently resulting from detrainment of moisture there when more cumulus entrainment is enforced in SAS/Tok.

\subsection{Equatorial wave vertical cross-section}

Vertical structure of the propagating wave in SAS/Tok was examined by composite analysis. Variables were composited for 60 days (days 30-90), following $850 \mathrm{hPa}$ convergence region with the constant phase speed of 13.6 degrees day $^{-1}$. Figure 13 shows the longitude-height structure of the eastward-moving 30-day wave averaged between $10^{\circ} \mathrm{S}$ and $10^{\circ} \mathrm{N}$. In the figures, $850 \mathrm{hPa} u$-wind convergence region is labeled as $180^{\circ} \mathrm{E}$, and the zonal mean is subtracted. The zonal $u$-wind (Fig. 13a) shows mainly first baroclinic structure, with the lower level convergence and upper level divergence at $180^{\circ} \mathrm{E}$, and has dominant zonal wavenumber 1 scale. Its maximum amplitudes are located at $700-850 \mathrm{hPa}$ in the lower troposphere, and $200 \mathrm{hPa}$ in the upper troposphere. The geopotential height anomaly (Fig. 13c) also shows first baroclinic structure, having opposite signs between the lower and upper troposphere. It has maximum amplitudes at $200 \mathrm{hPa}$ in the upper troposphere, but also it shows large amplitudes at the surface level. It is correlated negatively with the temperature anomaly in the lower troposphere (Fig. 13b), and lags the zonal wind but not by a full quarter wavelength. In the specific humidity anomaly (Fig. $13 \mathrm{~d}$ ), positive appear east of the $850 \mathrm{hPa}$ convergence region, and negative to the west. Large variability appears near the $500 \mathrm{hPa}$ level in the middle troposphere, as well as near the $850 \mathrm{hPa}$ level. It shows a westward tilted vertical structure, or upward development with time as the wave propagates east. The composite vertical structures shown in Fig. 13 are very similar to those obtained by Kuma (1994), who examined the 40-day wave composite structure in his aqua-planet GCM experiments, with a modified Kuo scheme. At this level of detail, these vertical structures are consistent with observations of the Madden-Julian oscillation (Hendon and Salby 1994; Wang and Schlesinger 1999).

\section{Eastward propagation mechanisms in the SAS/Tok control run}

The horizontal structure of the model ISO contains clues about its possible propagation 
(a) $U^{*}$

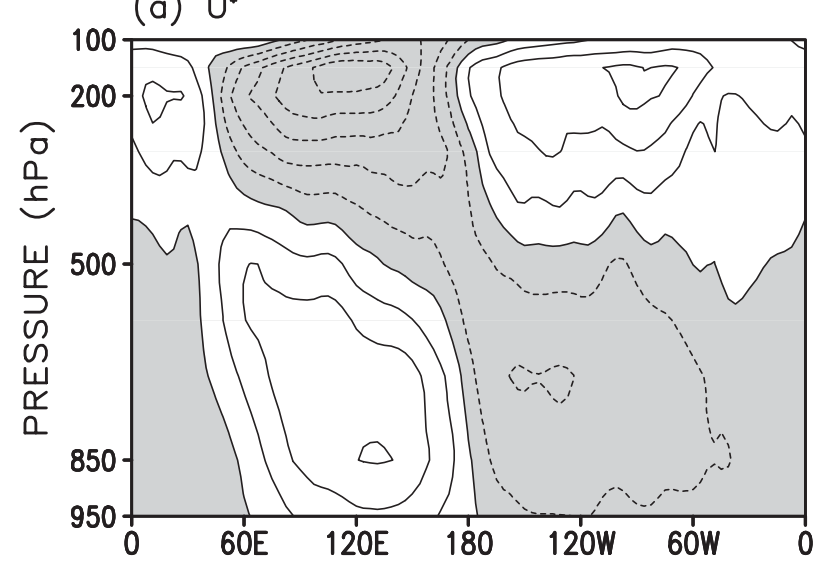

(c) $Z^{*}$

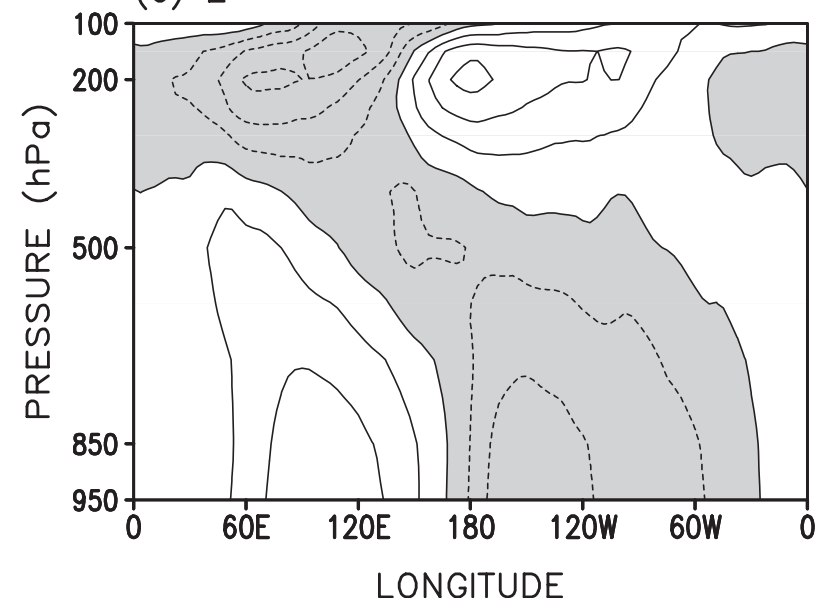

(b) $\mathrm{T}^{*}$

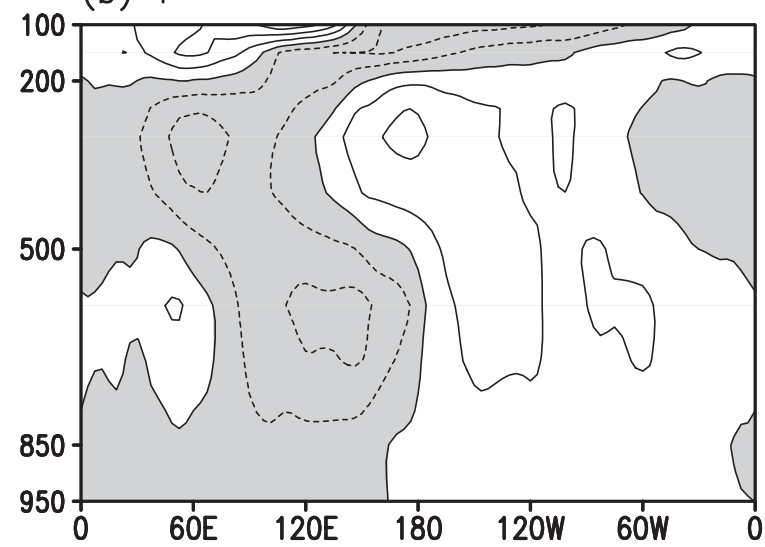

(d) $q^{*}$

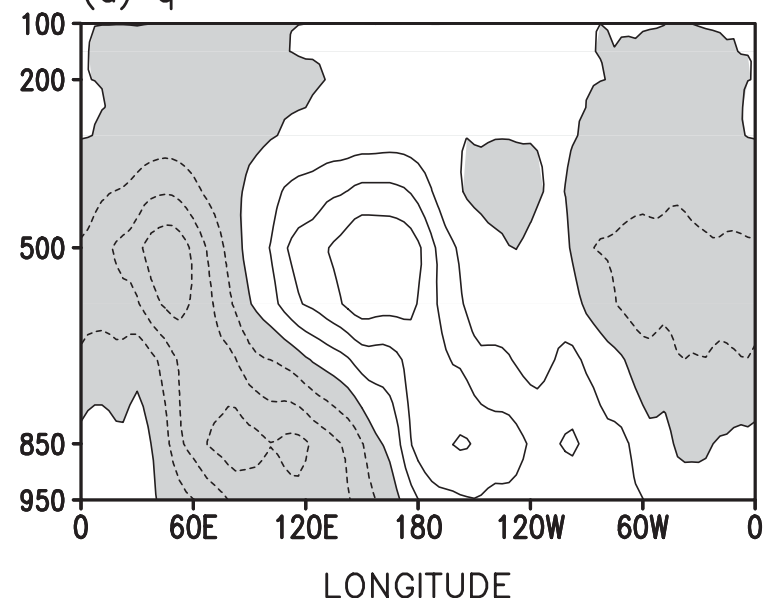

Fig. 13. Longitude-height composite structures of (a) zonal $u$-wind, (b) temperature, (c) geopotential height, and (d) specific humidity obtained from SAS/Tok. Composite is done for 60 days (30-90 day) following $850 \mathrm{hPa} u$-wind convergent area $\left(10^{\circ} \mathrm{S}-10^{\circ} \mathrm{N}\right)$, assuming a constant phase speed of $13.6^{\circ}$ per day. Zonal mean is removed from each variable and negative values are shaded and contoured with dashed lines. The contour intervals are $2 \mathrm{~m} \mathrm{~s}^{-1}$ for (a), $0.5 \mathrm{~K} \mathrm{for} \mathrm{(b),} 5 \mathrm{~m}$ for (c) and $2 \times 10^{-4} \mathrm{~kg} \mathrm{~kg}^{-1}$ for $(\mathrm{d})$.

mechanism. Figure 14 shows horizontal composite structures of precipitation rate, surface evaporation and $850 \mathrm{hPa}$ relative vorticity. The composite precipitation pattern (Fig. 14a) shows large-scale fluctuations with dominant zonal wavenumber 1 . Its maximum is centered near, and slightly west (behind) of the $850 \mathrm{hPa}$ $u$-wind convergence. To the west of the precipitation center, there are weak tail-shaped precipitating regions extending toward high latitudes from the equator, which may be due to the weak off-equatorial Rossby wave responses.
In surface evaporation (Fig. 14b), a negative anomaly appears to the east and positive to the west, in the enhanced westerlies between the Rossby gyres seen in the $850 \mathrm{hPa}$ vorticity field (Fig. 14c). Wind-evaporation feedback (Neelin et al. 1997) is therefore of the wrong sign to explain eastward propagation, consistent with results of Maloney (2002), and with observations (Lin and Johnson 1996). Moreover, evaporation has only small fluctuations compared to those of precipitation.

The frictional wave-CISK mechanism was 

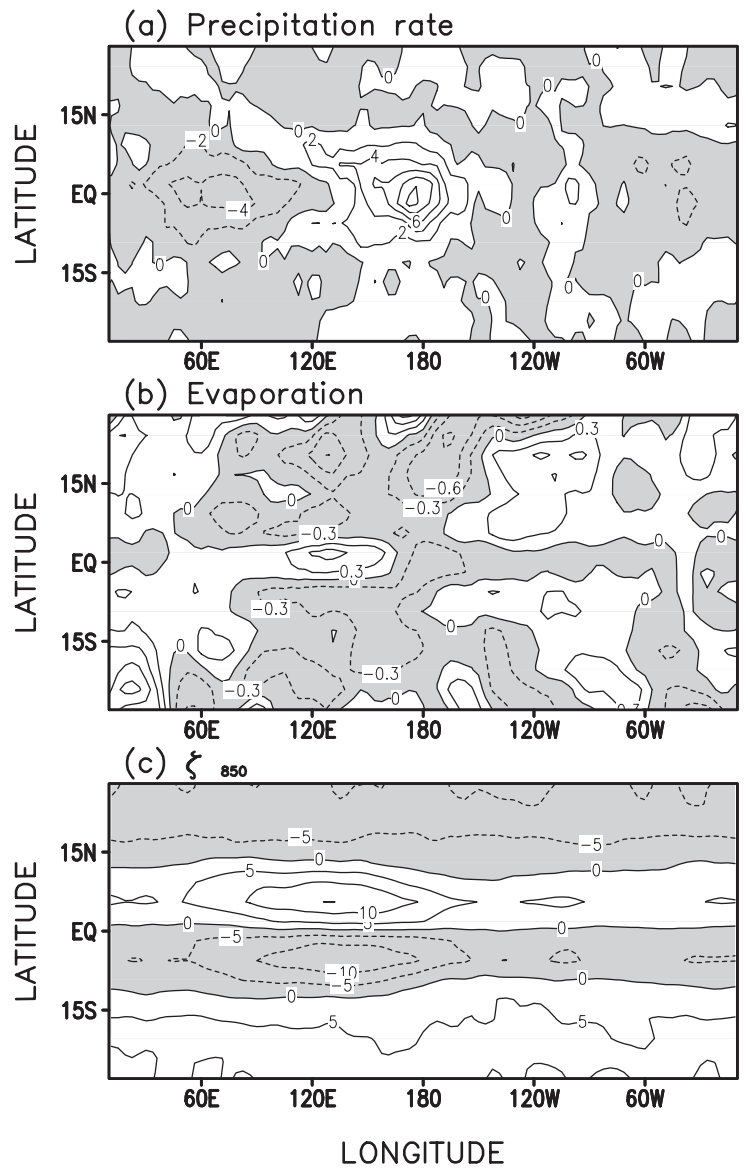

Fig. 14. Longitude-latitude composite diagrams of (a) precipitation rates $\left(\mathrm{mm}\right.$ day $\left.^{-1}\right)$, (b) surface evaporation $\left(\mathrm{mm} \mathrm{day}^{-1}\right)$, and (c) $850 \mathrm{hPa}$ relative vorticity $\left(10^{-6} \mathrm{~s}^{-1}\right)$ obtained from SAS/ Tok. Zonal means are removed in (a) and (b). Negative values are shaded and contoured with dashed lines in each figure.

demonstrated by Wang (1988) in a simple dynamic model with wave-CISK parameterization. He indicated that eastward moving waves increase moisture to the east, due to the meridional moisture flux convergence by surface friction. Using observations, Hendon and Salby (1994), and Maloney and Hartmann (1998) found that frictional wave-CISK likely plays a key role in the observed Madden-Julian (1972) oscillation. Moskowitz and Bretherton (2001) explored this mechanism in a more analytic context, noting that early work by Wang (1988) used surface friction an order of magnitude stronger than is realistic. Prior GCM studies (Kuma 1994; Maloney 2002) have also diagnosed the importance of equatorial frictional convergence in the boundary layer.

Frictional convergence is also prominent in our model, as shown in Fig. 15. In 850 and $950 \mathrm{hPa}$ levels, the geopotential height anomaly (Fig. 15a and b) shows Matsuno-Gill type structure, resembling a Kelvin wave near the equator, and Rossby wave structure in off the equator (Gill 1980). In the $850 \mathrm{hPa}$ wind vectors, zonal wave convergence dominates, while the meridional convergence is negligible. This indicates the Kelvin wave convergence in zonal direction. However, in the $950 \mathrm{hPa}$ level belonging to the PBL layer, surface friction induces a meridional component toward the equatorial low pressure. Figure $15 \mathrm{c}$ and $\mathrm{d}$ show moisture flux convergence at the 850 and $950 \mathrm{hPa}$ levels. At the $850 \mathrm{hPa}$ level, moisture convergence is in-phase with the wind convergence. In the $950 \mathrm{hPa}$ level, frictionally induced moisture convergence exists to the east of the $850 \mathrm{hPa}$ convergence regions and divergence to the west, with about twice the magnitude. The strong east-west asymmetry in the zonal direction could help the convective region move eastward.

Frictional convergence is very shallow. In the study of Maloney (2002), a Madden-Julian-like oscillation in the NCAR CCM3 model was produced with the McRAS convection scheme. In that study, enhanced convection shows a preference to occur within the $850 \mathrm{hPa}$ easterly wind anomaly, while observed convection tends to fall closer to the nodal point of the wind anomaly field. Maloney attributed this discrepancy from observations to the absence of parameterization of convective inhibition, pointing out that the McRAS deep convection may respond too quickly to the boundary layer moisture increases by frictional convergence. In our SAS/Tok run, surface moisture convergence (Fig. 15d) leads that of $850 \mathrm{hPa}$ level (Fig. 15c) by quite a bit, indicating that surface moisture convergence does not lead immediately to deep convection, but rather is stored for many days before deep convection develops. Inhibition by the critical entrainment rate constraint makes this storage more effective, as discussed in section 3.2. 

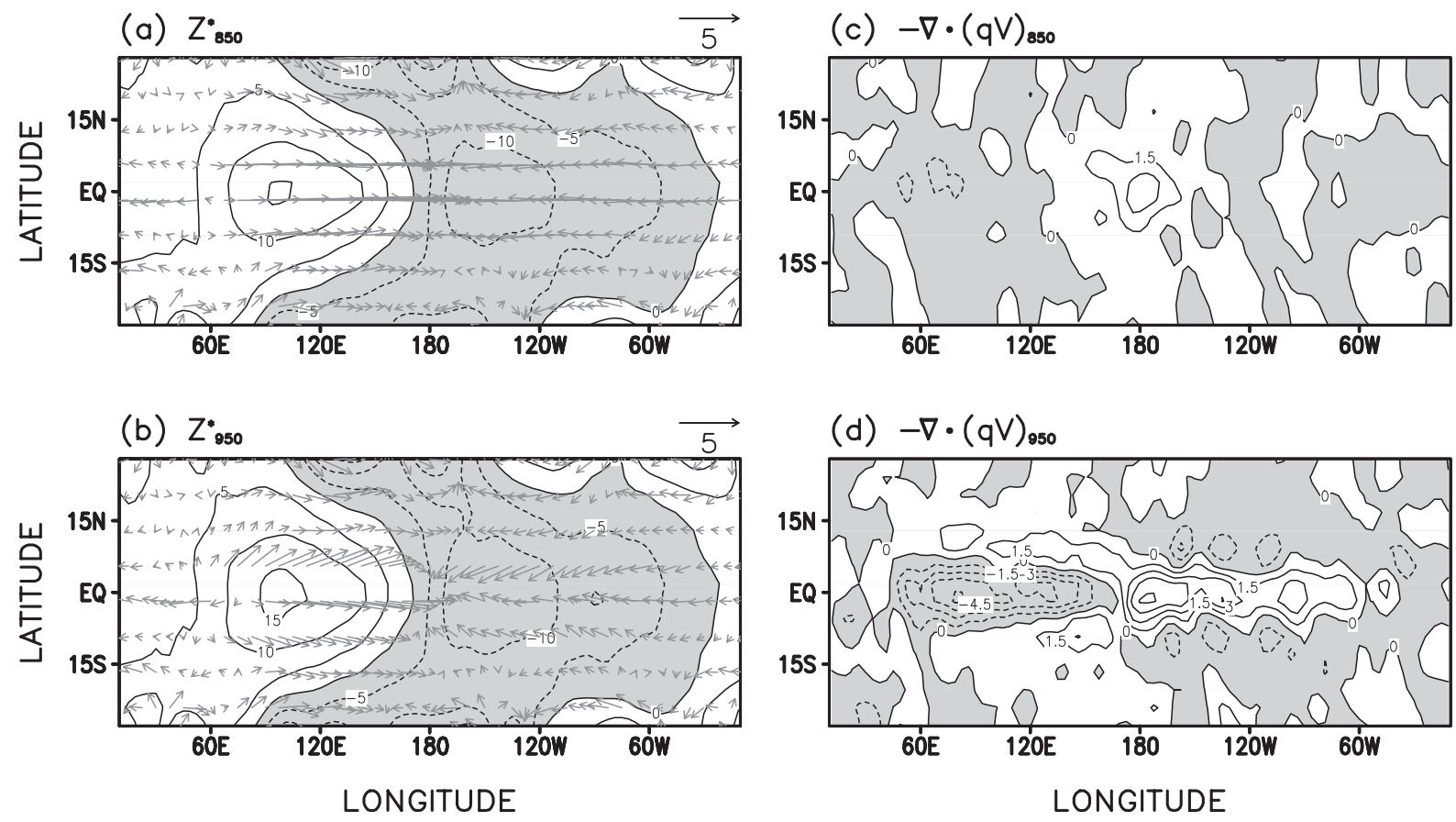

Fig. 15. Longitude-latitude composite diagrams of geopotential height (contour line, meter unit) and wind vector (arrows, $\mathrm{m} \mathrm{s}^{-1}$ ) at (a) $850 \mathrm{hPa}$ and (b) $950 \mathrm{hPa}$ levels. (c) and (d) indicate moisture flux convergence $\left(10^{-8} \mathrm{~s}^{-1}\right)$ at $850 \mathrm{hPa}$ and $950 \mathrm{hPa}$, respectively. Zonal mean is removed in each variable. Negative values are shaded and contoured with dashed lines in each figure.

\section{Realistic earth geography runs}

To see how the aqua-planet effects of the cumulus minimum entrainment constraint translate to Earth, realistic integrations were performed with the actual land-ocean distribution, observed sea surface temperatures containing the seasonal cycle, and fully interactive physics-such as cloud-radiation and landatmosphere feedbacks. The model was integrated twice for 32 months (1 January 1996-31 August 1998), once with unconstrained SAS scheme (standard), and the other with the cumulus entrainment constraint in equation (4), with $\alpha$ set to 0.1 (modified). The time mean rainfall structure is shown in Fig. 16, in which observed (GPCP, Huffman et al. 2001) precipitation rate is also given. The broad pattern and its zonal mean are quite similar among the two simulations and observations, but the modification gives overall increase of rainfall, especially in the midlatitude storm tracks, probably through indirect feedbacks, rather than directly parameterized convection there. Contrary to the aqua-planet experiment, the zonal mean distribution of precipitation rate in the standard run is not manifested by double ITCZ structure appeared in the aqua-planet run.

It is curious that ITCZ structure in the realistic AGCM experiments does not seem to be much affected by the cumulus entrainment rate constraint (Fig. 16b and c), unlike in the aquaplanet experiment. The geographical positioning of ITCZ in the real atmosphere can be also affected by many other factors: such as the underlying SST distribution, its meridional gradient and zonally asymmetric circulation due to the inclusion of realistic land masses, which do not give any simple explanation as in the aquaplanet case, with zonally symmetric boundary forcing. It is beyond the scope of this study to examine the origin of ITCZ positioning in the realistic simulation, but we just speculate that single ITCZ, typical in the Central and Eastern Pacific Ocean, may be largely due to observed off-equatorial SST maximum $\left(\sim 5^{\circ} \mathrm{N}\right)$, with sharp meridional gradients.

On the contrary, rainfall simulation of West- 

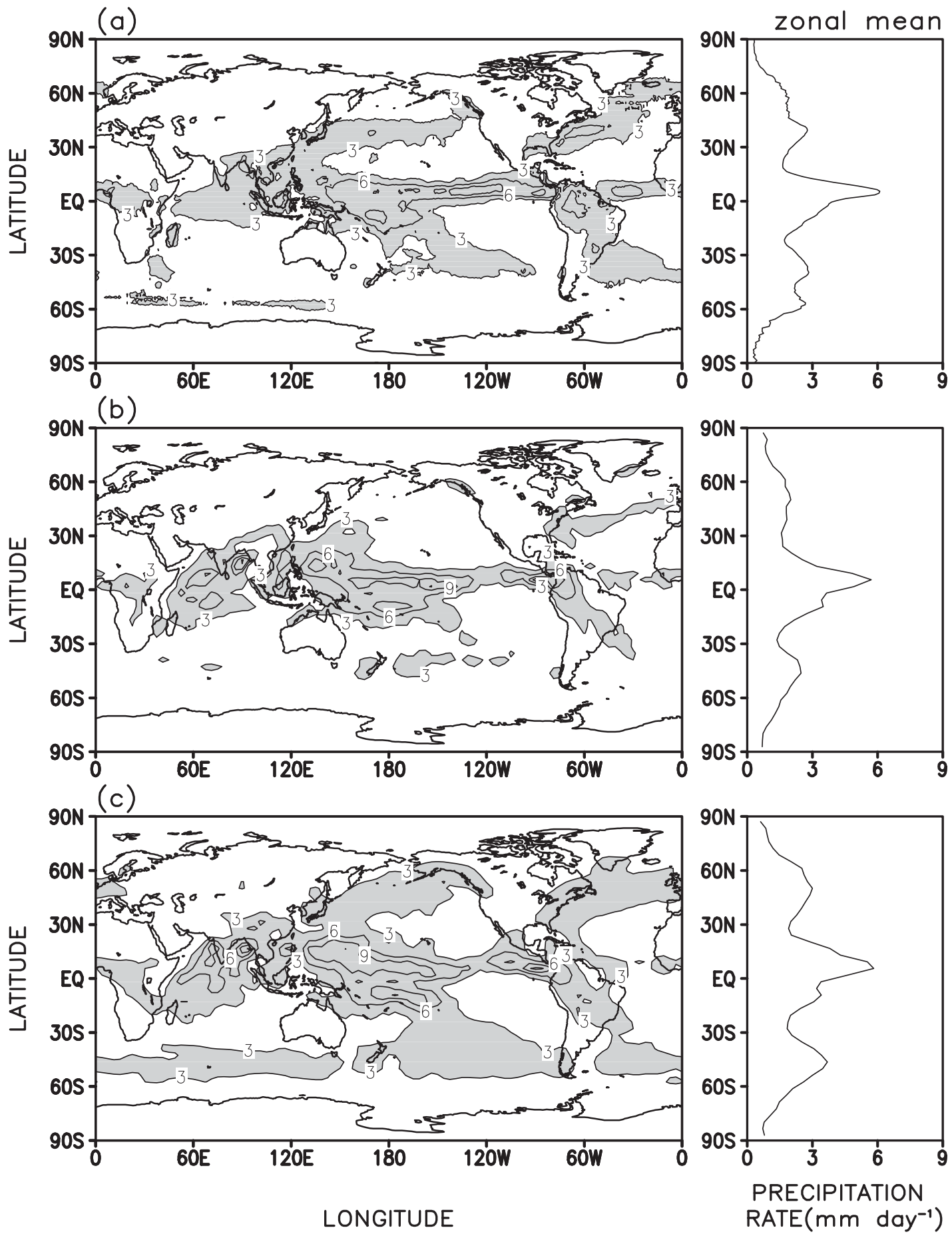

Fig. 16. Horizontal distributions of annual mean precipitation rate (left) and its zonal mean (right) in 1997 obtained from the (a) Global Precipitation Climatology Project (GPCP) one-degree daily (1DD) Reanalysis, (b) model simulation with the SAS scheme (standard run) and, (c) model simulation with the modified SAS scheme by the cumulus minimum entrainment rate constraint (modified run, $\alpha=0.1$ ). The contour intervals are $3 \mathrm{~mm}^{\text {day }}{ }^{-1}$ and values more than $3 \mathrm{~mm} \mathrm{day}^{-1}$ are shaded. 

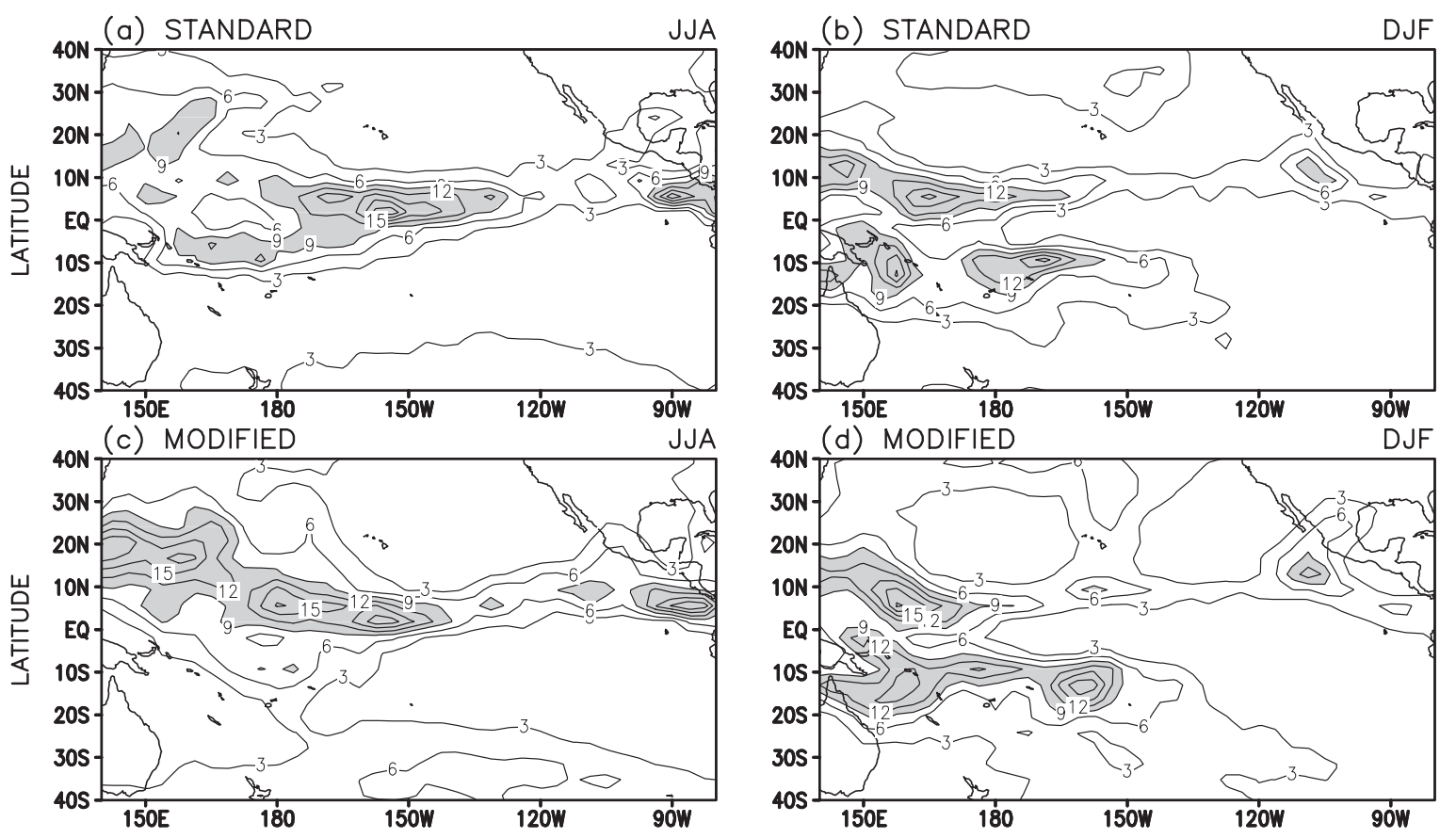

Fig. 17. Horizontal distributions of the (a) Northern Hemisphere summer (June-July-August 1997) and (b) winter (December-January-February 1997) mean precipitation rates $\left(\mathrm{mm} \mathrm{day}^{-1}\right)$ simulated in the standard run. (c) and (d) are same as in (a) and (b), respectively, except for the modified run. The contour intervals are $3 \mathrm{~mm} \mathrm{day}^{-1}$, and values more than $9 \mathrm{~mm}$ day $^{-1}$ are shaded in each figure.

ern Pacific region reveals some changes after cumulus entrainment modification. Annual mean rainfall just shows the slight increase in the modified case, but this is the result of distinguished seasonal migration of intensified ITCZ. Figure 17 compares the two realistic AGCM simulations of precipitation rate in the Pacific Ocean area $\left(40^{\circ} \mathrm{S}-40^{\circ} \mathrm{N}, 140^{\circ} \mathrm{E}-80^{\circ} \mathrm{W}\right)$ for the Northern Hemisphere summer (JuneJuly-August 1997), and winter (DecemberJanuary-February 1997). Compared with the standard case (SAS), the modified case (SAS/ Tok) shows the enhancement of ITCZ in the summer Hemisphere. Precipitation rate has been increased in the northern branch of convergence region around $10-20^{\circ} \mathrm{N}$ in the Northern Hemisphere summer, whereas the precipitation rate in the South Pacific Convergence Zone (SPCZ) around $10-20^{\circ} \mathrm{S}$, has been increased in the Northern Hemisphere winter. This indicates that the ITCZ has been strengthened by the cumulus entrainment modification.
Figure 18 shows longitude-time diagrams of daily precipitation rate in the equatorial region $\left(10^{\circ} \mathrm{S}-10^{\circ} \mathrm{N}\right)$ in 1997 . No time filter is applied to the daily mean precipitation rate in each figure, and therefore it contains seasonal variability as well as intraseasonal variability. Observed GPCP precipitation rate (Fig. 18a) shows larger temporal variability than the two AGCM simulations through the year, with sporadic increase of variability in the intraseasonal time scale, especially in the Northern Hemisphere spring and winter. In the standard simulation (Fig. 18b), temporal variability is pretty small, with largest rainfall covering the western Pacific region. Variability is increased in the modified run (Fig. 18c), but in lower frequencies and, still, much lower amplitude than the observations. Rainfall has more intense maxima, similar to the change in the aquaplanet experiment (Fig. 6). However, eastward movement of super cloud clusters (Nakazawa 1988) from the Indian Ocean to the western 


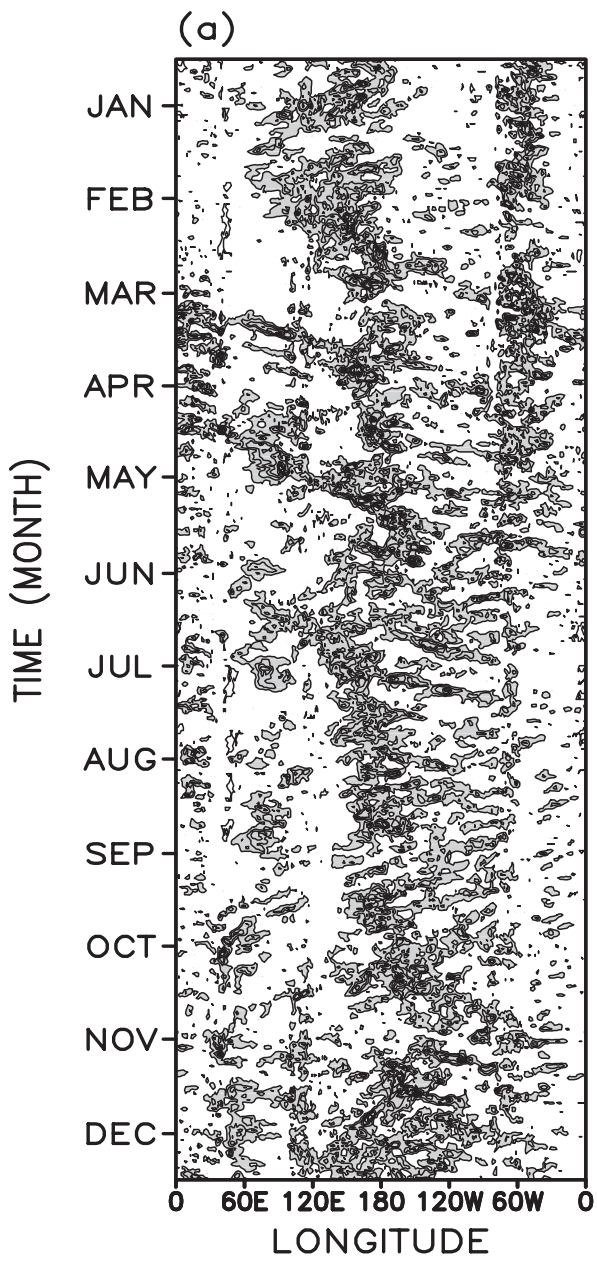

(b)

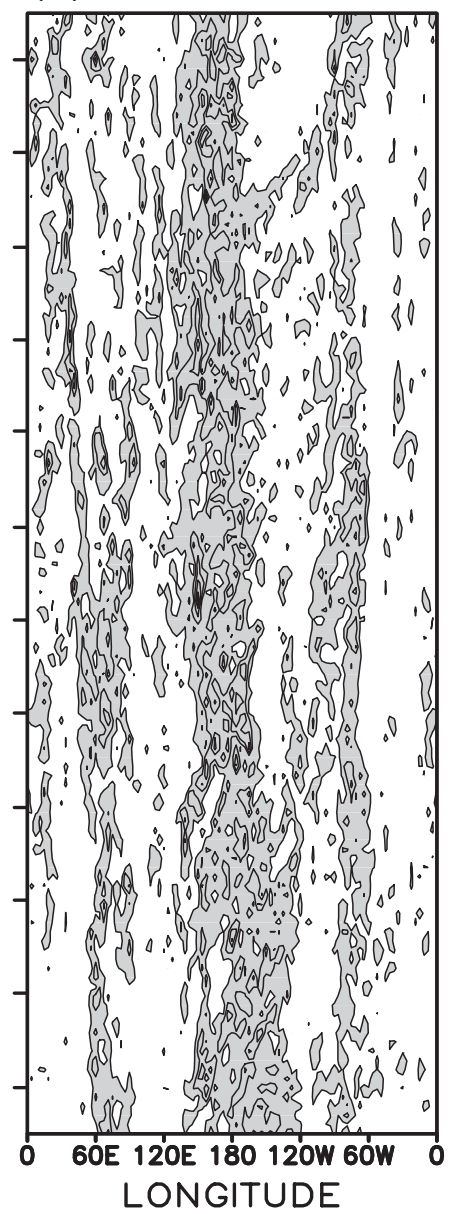

(c)

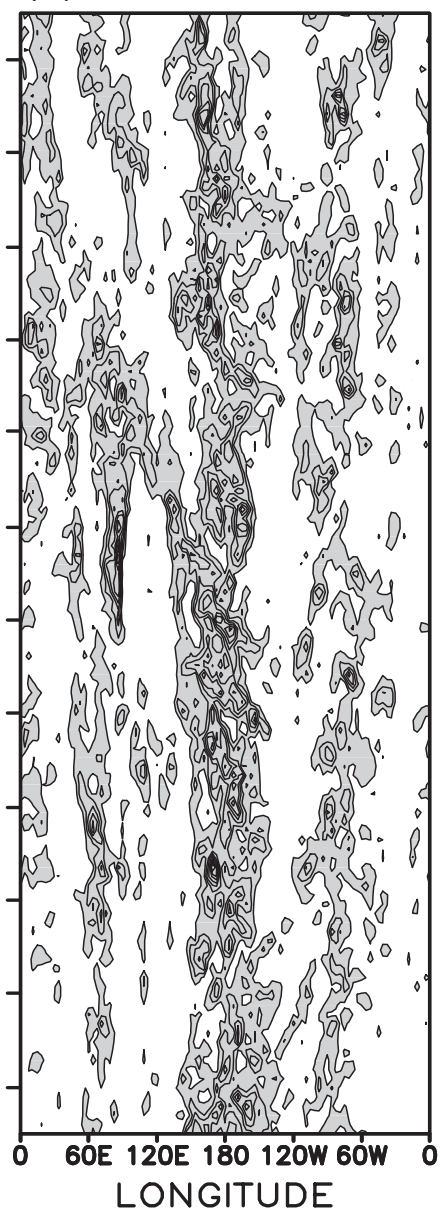

Fig. 18. Longitude-time diagrams of the daily averaged precipitation rates $\left(10^{\circ} \mathrm{S}-10^{\circ} \mathrm{N}\right)$ during 1997 obtained from the (a) GPCP 1DD Reanalysis, (b) standard run and (c) modified run. The contour intervals are $5 \mathrm{~mm}$ day $^{-1}$ and more than $5 \mathrm{~mm} \mathrm{day}^{-1}$ are shaded.

Pacific in the Northern Hemisphere springtime (March-June) in the observed, is not well simulated in the modified AGCM simulation.

The eastward movement is clearer in $200 \mathrm{hPa}$ velocity potential (Fig. 19), in which 15-70 day band pass filter is used to remove the seasonal cycle. In the NCEP/NCAR reanalysis data (Kalnay et al. 1996), eastward propagation of large-scale waves is clearly seen (Fig. 19a), particularly in Northern Hemisphere springtime (March-May). In the standard simulation, the overall ISO variability is much weaker than the observed, and the eastward propagation characteristics are not clear, as in the aquaplanet runs (Fig. 3). In the modified run, eastward propagating variations are prominent, somewhat stronger than the observations. The ISO seasonality-amplified in Northern Hemisphere spring in 1997-was not well reproduced. Instead, the modified run shows strong and fast propagating signals of large-scale wavenumber 1 , throughout the Northern Hemisphere winter.

Results of realistic AGCM integration demonstrate again that the zonal-mean climatology and ISO variability are closely related, and mutually dependent. As the mean convection becomes stronger in the tropical convergence region, by the modification of cumulus entrainment rate constraint, tropical ISO variability is apparently increasing in the modified simulation, which is consistent with the previous 

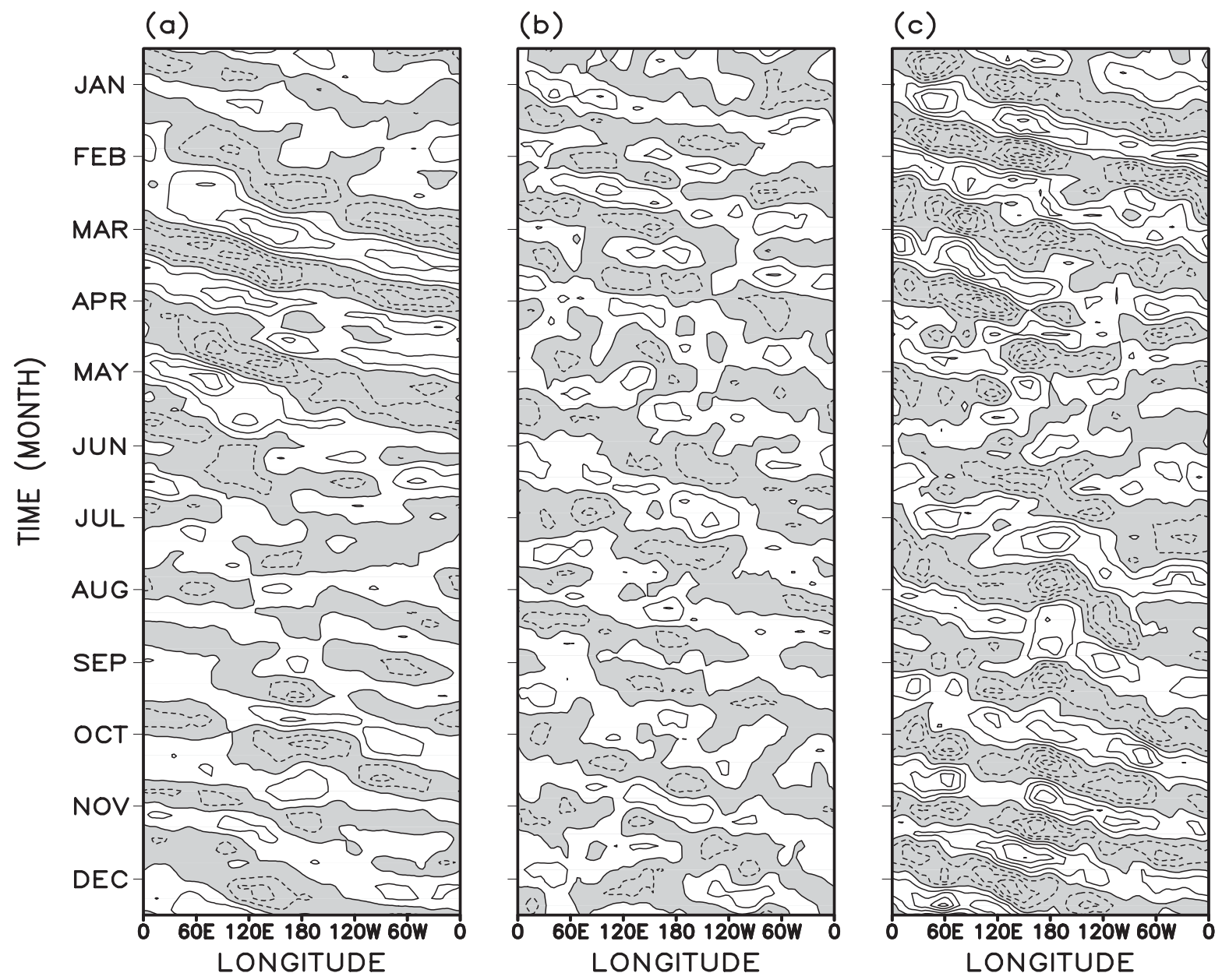

Fig. 19. Longitude-time diagrams of $200 \mathrm{hPa}$ velocity potential $\left(10^{\circ} \mathrm{S}-10^{\circ} \mathrm{N}\right)$ during 1997 obtained from the (a) NCEP/NCAR Reanalysis, (b) standard run, and (c) modified run. The velocity potential is 15-70 day filtered for eliminating seasonal cycle. The contour intervals are $3 \times 10^{6} \mathrm{~m}^{2} \mathrm{~s}^{-1}$, and negative values are shaded and contoured with dashed lines.

findings of the aqua-planet experiment (shown in Fig. 6 and 7). In the mean time, mean stability of the background state in the tropics $\left(20^{\circ} \mathrm{S}-20^{\circ} \mathrm{N}\right)$ has been decreased, due to the temperature decrease in the upper troposphere (not shown), which is quite similar in the aquaplanet case (Fig. 10).

\section{Discussions and conclusions}

In this study, the dependence of tropical intraseasonal oscillations (ISO) on cumulus parameterization, is investigated using aquaplanet AGCM experiments with three convection schemes: simplified Arakawa-Schubert
(SAS), Kuo (in the experiment called KUO), and moist convective adjustment (MCA) schemes. One of the major findings is that the characteristic of simulated variability is very different in each case. In the MCA and KUO runs, eastward propagating waves of precipitation and upper-level divergence on the equator, travel at a speed of $\sim 15 \mathrm{~m} \mathrm{~s}^{-1}$, corresponding to a 30 day around-the-globe period. In the SAS run, the precipitation has much weaker variability.

The mean thermodynamic state and tropical precipitation climatology also differ among the runs, in ways that are entangled with the variability, making interpretation more complicated. In particular, the zonal-mean rainfall 
has an equatorial maximum in MCA, whereas double rain belts (ITCZs) off the equator in the KUO and, especially, SAS runs. These latter two runs had a larger proportion of their variability in asymmetric (about the equator) modes, than did the runs with equator-centered convection. The KUO result is similar to that of Hess et al. (1993), where double-ITCZ climatology and asymmetric mixed Rossby-gravity wave variability, were found to be mutually supportive. Perhaps the same logic applies with equator-centered mean precipitation and symmetric equatorial (e.g., Kelvin wave) variability. The relationship between zonal mean climatology and tropical ISO variability, and how the modification of SAS scheme indirectly affects the ISO variability through the mean state change are further discussed below.

Zonal-mean evaporation looked similar in all tested aqua-planet cases, with prominent minima straddling the equator, apparently because of the small Coriolis parameter there. In light of this fact, the equator-peaked rainfall climatology of the MCA run implies that moisture is stored in the atmosphere, and transported long distances over warm tropical waters, but less so in the KUO run and least in the SAS run. This order is the same as that for the amplitude of the transient variability appeared in longitudinal rainfall variations, which must also involve moisture storage and transport. Following Ose et al. (1989), our interpretation is that deep convection schemes, which are quite unconstrained (like SAS with its undiluted plumes allowed), tend to make short-circuit in such moisture storage and transport mechanisms, causing the precipitation pattern to look more like the evaporation pattern with its equatorial minimum. This interpretation is supported by composite moist static energy profiles in rainy and dry regions (Fig. 10). The SAS scheme produces little humidity variation, with a very dry troposphere even in rainy regions, because cumulus plumes with little entrainment are allowed to operate, and they can retain buoyancy to high altitudes, even in such dry environments. At the other extreme, the MCA scheme requires saturation on the grid scale to operate.

The foregoing suggests that more stringent constraints on the SAS scheme might increase transient tropical variability, as well as equatorial precipitation amount. Following Tokioka et al. (1988) and Ose et al. (1989), a critical (minimum) entrainment rate was introduced in the SAS scheme, for runs labeled 'SAS/Tok'. With this change, eastward moving long waves of equatorial precipitation emerged clearly, with the typical speed for ISO in this model (30-day period). The entrainment constraint inhibits deep convection in dry regions, thus allowing moisture to accumulate (Fig. 10) before rain events. Furthermore, a single tropical rainfall belt was simulated in the equatorial region in the SAS/Tok case. These results are consistent with other studies, with a critical moisture convergence used by Itoh (1989), and a critical relative humidity used by Wang and Schlesinger (1999). Other parameters such as the relaxation time scale specified in SAS could also be used as a cumulus inhibition mechanism. Chao and Deng (1998) discussed the sensitivity of ISO variability to the relaxation time scale of SAS, and found that large-scale condensation takes over, and produces super cloud clusters as the relaxation time scale is increased in their two dimensional model.

Another way to think about the SAS/Tok findings is that in an ensemble of cumulus clouds parameterized in the SAS scheme, low- $\mu$ (less entraining) and high- $\mu$ (more entraining) clouds compete with each other for each increment of moisture that enters the PBL, in the near-neutral stability areas of the deep tropics. Suppose the SAS relaxation is very efficient. Then the sounding will be kept very close to neutral and the cloud work function $(A)$ can be nearly zero $(A \sim 0)$ for the least-diluted plume (deep convection). That same sounding will tend to have negative $A$ for plumes with higher entrainment rates (shallow convection). An increment of moisture in the PBL will produce positive cloud work function $(A>0)$ for the undiluted cloud, but will produce no positive $A$, but just less-negative for higher- $\mu$ clouds. In general, the competition among the cumuli is decided on the magnitude of cloud-base mass flux $\left(M_{B}\right)$, which again depends on $A /\left(A-A^{\prime}\right)$ (see equation (3) of section 2). However this is the case for non-negative $A$, and $A$ should be positive $(A>0)$ to produce positive cloud-base mass flux. In the scheme (Numaguti et al. 1995), the plumes with negative cloud work function are not taken into consideration, giving zero cumulus base mass flux. Therefore 
the deep cloud is more advantageous in this shallow-deep cumuli competition. The result is the SAS run's deep convective drizzle, with each increment of destabilization (by surface moisture flux) going directly into undiluted precipitating deep clouds, rather than to shallow clouds which could transport it into the lower-middle troposphere. With the critical entrainment rate constraint, undiluted plumes are excluded from the competition. Then, deep convection requires a sufficiently humid environment so that plumes with the minimum entrainment rate can remain buoyant up to the upper troposphere. Moisture accumulation within the boundary layer, and hence growing of PBL, also helps nearly undiluted plumes operate by the decrease of entrainment threshold values in equation (4).

One side effect of constraining the deep convection scheme is that it increases the amount of condensation heating by the large-scale cloud scheme. The highly-constrained MCA scheme, for example, only activates under conditions in which grid-scale moist overturning would begin anyway (saturated and conditionally unstable). As a result, it produces only about half the condensation heating in tropical rainfall (Fig. 12), and the MCA simulation of ISO has characteristics like that of a run with no convection scheme at all (not shown; see Numaguti and Hayashi 2000). Comparing SAS and SAS/Tok runs, the heating by large-scale condensation is greater in the latter case. Tokioka et al. (1988) and Wang and Schlesinger (1999) also showed that the contribution by other condensation processes (middle convection and large-scale condensation), increases as stronger criteria are imposed for the occurrence of deep convection. Randall et al. (1989) discuss in detail the interactions among condensation parameterizations in a GCM.

Despite the apparently complicated compensation between heating by convection and largescale condensation schemes, the profile of total diabatic heating in disturbances is relatively smooth and similar among the cases. This includes not only the runs here, with fixed radiation, but is also seen in Lee et al. (2001, figure $7 \mathrm{~d}$ ), in which the compensation is among 3 terms: convection, large-scale condensation, and cloudy radiative heating. Evidently, some largescale constraints act to simplify the profile of total heating in the model ISO, so that it is resistant to change by simply adjusting individual parameterizations. This has profound implications for the motivating idea of these studies: that the path to improved ISO simulation lies through individually improving the physical schemes representing the dominant deep tropical diabatic heating terms.

The profile of diabatic heating is thought to be an important factor in determining the propagation and stability properties of largescale tropical disturbances, as reviewed in the introduction. The heating profiles of all runs of this model are insufficiently top-heavy compared to anomalous heating profiles in the observed Madden-Julian oscillation (MJO), a shortcoming typical of many models, as shown by Lin et al. (2003). Also typical of many models, the ISO in all runs propagates much faster than the MJO, at a nearly constant speed closer to that of observed moist Kelvin waves (Wheeler and Kiladis 1999). If not by deep convection or radiation schemes, how might the diabatic heating profile in model disturbances be made more top-heavy?

To make deep convective heating more topheavy, perhaps attention should turn not to deep heating processes, but rather to the weaker, widespread process of shallow convection. In this model, the shallow convection scheme explicitly assumes no precipitation: it is parameterized simply as a mixing process. However, it is clear from both the indirect evidence of large-scale budget considerations (Mapes 2000 appendix), and direct radar observations (Short and Nakamura 2000) that latent heating by precipitating shallow cumulus clouds is a substantial part of the heat balance of the tropical lower troposphere. To some extent, the large-scale condensation scheme produces mean heating in the lowermost troposphere, similar in all these runs (not shown). This heating does not vary much intraseasonally, so it does not appear significant in Fig. 12 except in the KUO run. This large-scale rain is unrealistic over a global tropical warm pool, but perhaps is trying to compensate for the lack of precipitating shallow convection.

If shallow convection heats the lower-middle troposphere more strongly through latent heat release, the mean deep convective heating will necessarily have a more top-heavy profile by 
radiative-convective equilibrium considerations in the tropics. The perturbation heating would likely follow, with perhaps beneficial effects on the dynamics of disturbances. Evidence for this reasoning is found in the results of Inness et al. (2001), where increased vertical resolution in a GCM caused stronger and better intraseasonal variability. The mechanism was that stable layers induced by melting of solid precipitation (diabatic cooling), as it falls from upper levels and passes the $0^{\circ} \mathrm{C}$ melting level in the middle troposphere, were better resolved at the increase of vertical resolution, which strongly enhanced the parameterized population of precipitating cumulus clouds of half-troposphere depth. Although this mechanism appears in that particular model to be mediated somewhat by a numerical artifact of the vertical grid staggering (vertical "ringing"; compare their lapse rate figure with Fig. 4 of Arakawa and Konor 1996), it still serves to illustrate the causal connection between half-depth cumulus clouds and the ISO.

Other mechanisms than just the interaction of deep wave structures with deep heating are also apparently at work in intraseasonal variability. Based on a composite analysis following the propagating wave, the frictional waveCISK (Wang 1988) mechanism was found to be operating in the SAS/Tok simulation, with frictional convergence to the east, and the divergence to the west of precipitating region in the PBL region, due to Kelvin-wave surface pressure anomalies. The evaporation-wind feedback mechanism (Neelin et al. 1997) is of the wrong sign to explain propagation, as evaporative flux is enhanced to the west of existing convection.

Finally, resolution dependence must be mentioned. Hayashi and Golder (1986), and Kuma (1994), suggested that the horizontal resolution of the model should be increased to improve ISO simulations. In our case, the horizontal resolution was found to be less critical. When the resolution is increased from $\mathrm{T} 31\left(\sim 3.75^{\circ}\right)$ to T106 $\left(\sim 1.125^{\circ}\right)$, the double ITCZ structure still appears in the high-resolution aqua-planet simulation, as in the lower-resolution case. Also, the behavior of the convective disturbances and large-scale waves were not critically changed.

To summarize this study, the major conclusions are listed below:
1) The simulated intraseasonal variability and propagation characteristics are significantly different among the aqua-planet experiments with different cumulus schemes in a model: more restricted convection criteria produce stronger intraseasonal variability.

2) Mean thermodynamic state and tropical ITCZ structures also vary among the simulations, demonstrating that the ISO variability and the mean state are mutually related in such a way that transient disturbances are apparently increasing as the mean convection becomes more concentrated on the equator, subject to the organized moist Kelvin waves.

3) In a zonal-mean moisture transport sense, unconstrained deep convection schemes tend to make short-circuit from the off-equatorial evaporating regions, inducing weak tropical ISO variability due to the small moisture accumulation in tropics. By constraining deep convection with the cumulus entrainment threshold in the simplified ArakawaSchubert scheme, the tropical ISO variability increases substantially with a single ITCZ structure.

4) The vertical profiles of ISO-varying heating are broadly similar with middle-heavy structures, but with varying combinations of convective and large-scale condensation terms, in which more constrained cumulus scheme gives larger role to the large-scale condensation process.

5) The frictional wave-CISK mechanism operates in the aqua-planet ISO simulation, whereas the evaporation-wind feedback is not evident in explaining the eastward propagation of simulated waves.

6) The modification of minimum cumulus entrainment rate in the simplified ArakawaSchubert scheme, produces more strong tropical ISO variability in a realistic AGCM integration, with enhanced rainfall in the ITCZ region and more unstable background stratification.

This study demonstrates that the cumulus parameterization remains a key issue for improving AGCM simulations of both mean tropical rainfall and its intraseasonal variability. Limiting undiluted deep convection in the SAS scheme appears to be a step in the right direc- 
tion. However, improving model simulations of deep-convective disturbances in AGCMs may require attention beyond the obvious, locally large tendency terms in deep convective regions. Subtler issues include the competition between deep and shallow convection, and the partition within shallow convective clouds between vertical moisture transport and heating of the lower troposphere through precipitation. Work in these areas is being pursued currently.

\section{Acknowledgements}

We would like to thank two anonymous reviewers for their valuable comments. This study was supported by the Climate Environment System Research Center sponsored by the SRC program of Korea Science and Engineering Foundation. BEM was supported by NSF grants ATM-0112715 ATM-0097116 and ATM0073206, and benefited from discussions with Dr. Jialin Lin.

\section{References}

Arakawa, A., 1972: Design of the UCLA general circulation model. Numerical simulation of weather and climate. Tech. Rep. 7, Dept. of Meteorology, UCLA. 116p.

Arakawa, A. and W.H. Schubert, 1974: Interaction of a cumulus cloud ensemble with the large scale environment. Part I. J. Atmos. Sci., 31, 674701.

- and C.S. Konor, 1996: Vertical differencing of the primitive equations based on the CharneyPhillips grid in hybrid-p vertical coordinates. Mon. Wea. Rev., 124, 511-528.

Bonan, G.B., 1996: A land surface model (LSM version1.0) for ecological, hydrological, and atmospheric studies: technical description and users's guide. NCAR Technical Note NCAR/ $T N-417+S T R$. National Center for Atmospheric Research, Boulder, Colorado, 150pp.

Chang, C.P. and H. Lim, 1988: Kelvin wave-CISK: A possible mechanism for 30-50 day oscillations. J. Atmos. Sci., 45, 1709-1720.

Chao, W.C. and L. Deng, 1998: Tropical intraseasonal oscillation, super cloud clusters, and cumulus convection schemes. Part II: 3D aquaplanet simulations. J. Atmos. Sci., 55, 690709.

Cho, H.-R. and D. Pendlebury, 1997: Wave CISK of equatorial waves and the vertical distribution of cumulus heating, J. Atmos. Sci., 54, 24292440 .

Gates, W.L., 1992: AMIP: The Atmospheric Model
Intercomparison Project. Bull. Amer. Meteor. Soc., 73, 1962-1970.

Gill, A.E., 1980: Some simple solutions for heatinduced tropical circulation. Quart. J. Roy. Meteor. Soc., 106, 447-463.

Hayashi, Y., 1982: Space-time spectral analysis and its application to atmospheric waves. J. Meteor. Soc. Japan, 60, 156-171.

and D.G. Golder, 1986: Tropical intraseasonal oscillations appearing in a GFDL general circulation model and FGGE data. Part I: Phase propagation. J. Atmos. Sci., 43, 3058-3067.

and A. Sumi, 1986: The 30-40 day oscillations simulated in an "aqua-planet" model. $J$. Meteor. Soc. Japan, 64, 451-466.

Hendon, H.H. and M.L. Salby, 1994: The life cycle of the Madden-Julian oscillation. J. Atmos. Sci., 51, 2225-2237.

Hess, P.G., D.S. Battisti, and P.J. Rasch, 1993: Maintenance of the intertropical convergence zones and the large-scale tropical circulation on a water-covered earth. J. Atmos. Sci., 50, 691-713.

Holtslag, A.A.M. and B.A. Boville, 1993: Local versus nonlocal boundary-layer diffusion in a global climate model. J. Climate, 6, 1825-1842.

Huffman, G.J., R.F. Adler, M.M. Morrissey, D.T. Bolvin, S. Curtis, R. Joyce, B. McGavock, and J. Susskind, 2001: Global precipitation at onedegree daily resolution from multisatellite observations. J. Hydrometeorology, 2, 36-50.

Inness, P.M., J.M. Slingo, S.J. Woolnough, R.B. Neale, and V.D. Pope, 2001: Organization of tropical convection in a GCM with varying vertical resolution: Implications for the simulation of the Madden-Julian oscillation. Clim. Dyn., 17, 777-793.

Itoh, H., 1989: The mechanism for the scale selection of tropical intraseasonal oscillations. Part I: Selection of wavenumber 1 and the three-scale structure. J. Atmos. Sci., 46, 1779-1798.

Kalnay, E., M. Kanamitsu, R. Kistler, W. Collins, D. Deaven, L. Gandin, M. Iredell, S. Saha, G. White, J. Woolen, Y. Zhu, M. Chelliah, W. Ebisuzaki, W. Higgins, J. Janowiak, K.C. Mo, C. Ropelewski, J. Wang, A. Leetmaa, R. Reynolds, R. Jenne, and D. Joseph, 1996: The NCEP/ NCAR 40-year reanalysis projects. Bull. Amer. Meteor. Soc., 77, 437-471.

Kim, J.-K., I.-S. Kang, and C.-H. Ho, 1998: East Asian summer monsoon simulated by the Seoul National University GCM. Proc. International Conference on Monsoon and Hydrologic Cycle. 227-231.

Kuma, K., 1994: The Madden and Julian oscillation and tropical disturbances in an aqua-planet version of JMA global model with T63 and 
T159 resolution. J. Meteor. Soc. Japan, 72, 147-172.

Kuo, Y.H., 1974: Further studies of the parameterization of the influence of cumulus convection of large-scale flow. J. Atmos. Sci., 31, 12321240.

Lau, K.M. and L. Peng, 1987: Origin of low frequency (intraseasonal) oscillations in the tropical atmosphere. Part I: The basic theory. J. Atmos. Sci., 44, 950-972.

Lee, M.-I., I.-S. Kang, J.-K. Kim, and B.E. Mapes, 2001: Influence of cloud-radiation interaction on simulating tropical intraseasonal oscillation with an atmospheric general circulation model. J. Geophys. Res., 106, D13, 14219-14234.

Le Treut, H. and Z.-X. Li, 1991: Sensitivity of an atmospheric general circulation model to prescribed SST changes: feedback effects associated with the simulation of cloud optical properties. Clim. Dyn., 5, 175-187.

Lin, X. and R.H. Johnson, 1996: Kinematic and thermodynamic characteristics of the flow over the western Pacific warm pool during TOGA COARE. J. Atmos. Sci., 53, 695-715.

Lin, J., B.E. Mapes, M. Zhang, and M.E. Newman, 2003: Stratiform precipitation, heating profiles, and the Madden-Julian oscillation. J. Atmos. Sci., submitted.

Madden, R.A. and P.R. Julian, 1971: Detection of a 40-50 day oscillation in the zonal wind in the tropical Pacific. J. Atmos. Sci., 28, 702-708.

Maloney, E.D., 2002: An intraseasonal oscillation composite life cycle in the NCAR CCM3.6 with modified convection. J. Climate, 15, 964982.

and D.L. Hartmann, 1998: Frictional moisture convergence in a composite life cycle of the Madden-Julian oscillation. J. Climate, 11, 2387-2403.

and 2001: The sensitivity of intraseasonal variability in the NCAR CCM3 to changes in convective parameterizations. $J$. Climate, 14, 2015-2034.

Manabe, S.J., J.S. Smagorinsky, and R.F. Stricker, 1965: Simulated climatology of a general circulation model with a hydrological cycle. Mon. Wea. Rev., 93, 769-798.

Mapes, B.E., 2000: Convective inhibition, subgridscale triggering energy, and stratiform instability in a toy tropical wave model. J. Atmos. Sci., 57, 1515-1535.

McFarlane, N.A., 1987: The effect of orographically excited wave drag on the general circulation of the lower stratosphere and troposphere. $J$. Atmos. Sci., 44, 1775-1800.

Moorthi, S. and M.J. Suarez, 1992: Relaxed ArakawaSchubert: a parameterization of moist convec- tion for general circulation models. Mon. Wea. Rev., 120, 978-1002.

Moskowitz, B.M. and C.S. Bretherton, 2000: An analysis of frictional feedback on a moist equatorial Kelvin mode. J. Atmos. Sci., 57, 21882206.

Nakajima, T. and M. Tanaka, 1986: Matrix formulation for the transfer of solar radiation in a plane-parallel scattering atmosphere. J. Quant. Spectrosc. Radiat. Transfer, 35, 13-21.

Nakazawa, T., 1988: Tropical super clusters within intraseasonal variations over the western $\mathrm{Pa}$ cific. J. Meteor. Soc. Japan, 66, 823-839.

Neelin, J.D., I.M. Held, and K.H. Cook, 1987: Evaporation-wind feedback and low-frequency variability in the tropical atmosphere. $J$. Atmos. Sci., 44, 2341-2348.

Numaguti, A., M. Takahashi, T. Nakajima, and A. Sumi, 1995: Development of an atmospheric general circulation model. In Reports of a New Program for Creative Basic Research Studies, Studies of Global Environment Change with Special Reference to Asia and Pacific Regions, Rep. I-3, Center for Climate System Research, Tokyo, 1-27.

and Y. Hayashi, 2000: Gravity-wave dynamics of the hierarchical structure of super cloud clusters. J. Meteor. Soc. Japan, 78, 301-331.

Ose, T., T. Tokioka, and K. Yamazaki, 1989: Hadley circulations and penetrative cumulus convection. J. Meteor. Soc. Japan, 67, 605-619.

Randall, D.A., Harshvardhan, D.A. Dazlich, and T.G. Corsetti, 1989: Interactions among radiation, convection, and large-scale dynamics in a general circulation model. J. Atmos. Sci., 46, 1943-1970, 1989.

Short, D.A. and K. Nakamura, 2000: TRMM radar observations of shallow precipitation over the tropical oceans. J. Climate, 13, 4107-4124.

Slingo, J.M. and Coauthors, 1996: Intraseasonal oscillations in 15 atmospheric general circulation models: Results from an AMIP diagnostic subproject. Clim. Dyn., 12, 422-479.

Sud, Y.C. and G.K. Walker, 1999: Microphysics of clouds with the relaxed Arakawa-Schubert scheme (McRAS). Part I: Design and evaluation with GATE phase III data. J. Atmos. Sci., 56, 3196-3220.

Swinbank, R., T.N. Palmer, and M.K. Davey, 1988: Numerical simulation of the Madden and Julian oscillations. J. Amos. Sci., 45, 774-788.

Takahashi, M., 1987: A theory of slow phase speed of the intraseasonal oscillation using the waveCISK. J. Meteor. Soc. Japan, 65, 43-49.

Tiedtke, M., 1983: The sensitivity of the time-mean large-scale flow to cumulus convection in the ECMWF model. Workshop on Convection in 
Large-Scale Numerical Models. ECMWF, 28 Nov-1 Dec 1983, pp297-316.

Tokioka, T., K. Yamazaki, A. Kitoh, and T. Ose, 1988: The equatorial 30-60 day oscillation and the Arakawa-Schubert penetrative cumulus parameterization. J. Meteor. Soc. Japan, 66, 883-901.

Waliser, D.E., K.M. Lau, and J.H. Kim, 1999: The influence of coupled sea surface temperatures on the Madden-Julian oscillation: A model perturbation experiment. J. Atmos. Sci., 56, 333-358.
Wang, B., 1988: Dynamics of the tropical lowfrequency waves: An analysis of the moist Kelvin wave. J. Atmos. Sci., 45, 2051-2065.

Wang, W. and M.E. Schlesinger, 1999: The dependence on convection parameterization of the tropical intraseasonal oscillation simulated by the UIUC 11-layer atmospheric GCM. J. Climate, 12, 1424-1457.

Wheeler, M. and G.N. Kiladis, 1999: Convectively coupled equatorial waves: analysis of clouds and temperature in the wavenumber-frequency domain. J. Atmos. Sci., 56, 374-399. 